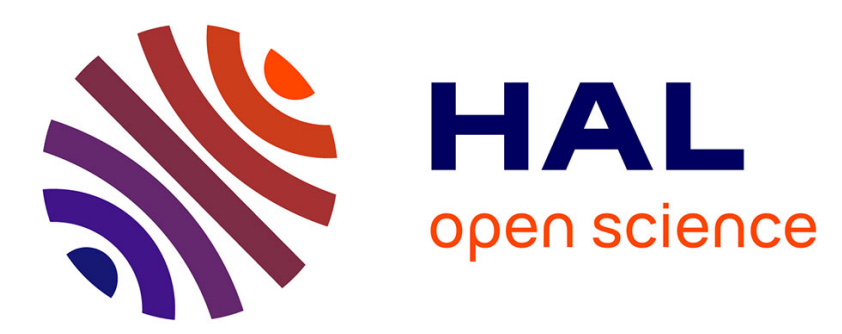

\title{
Modeling Interactions between an Amino Acid and a Metal Dication: Cysteine-Calcium(II) Reactions in the Gas Phase
}

\author{
Marcela Hurtado, Monte Manuel, Al Mokhtar Lamsabhi, Manuel Yáñez, \\ Otilia Mó, Jean-Yves Salpin
}

\section{To cite this version:}

Marcela Hurtado, Monte Manuel, Al Mokhtar Lamsabhi, Manuel Yáñez, Otilia Mó, et al.. Modeling Interactions between an Amino Acid and a Metal Dication: Cysteine-Calcium(II) Reactions in the Gas Phase. ChemPlusChem, 2013, 78 (9), pp.1124-1133. 10.1002/cplu.201300166 . hal-01083257

\section{HAL Id: hal-01083257 https://hal.science/hal-01083257}

Submitted on 8 Oct 2018

HAL is a multi-disciplinary open access archive for the deposit and dissemination of scientific research documents, whether they are published or not. The documents may come from teaching and research institutions in France or abroad, or from public or private research centers.
L'archive ouverte pluridisciplinaire HAL, est destinée au dépôt et à la diffusion de documents scientifiques de niveau recherche, publiés ou non, émanant des établissements d'enseignement et de recherche français ou étrangers, des laboratoires publics ou privés. 


\title{
Modeling Interactions between an Amino Acid and a Metal Dication: Cysteine- Calcium(II) Reactions in the Gas Phase
}

Marcela Hurtado $^{1}$, Manuel Monte ${ }^{2}$, Al Mokhtar Lamsabhi ${ }^{1 *}$, Manuel Yáñez ${ }^{1}$, Otilia Mó ${ }^{1}$, Jean-Yves $\operatorname{Salpin}^{3,4 *}$

1 Departamento de Química, C-9. Universidad Autónoma de Madrid. Cantoblanco, 28049 Madrid, Spain

2 Instituto de Catálisis y Petroleoquímica, CSIC, C/ Marie Curie 2, Campus de Cantoblanco, 28049 Madrid, Spain

3 Université d'Evry Val d'Essonne, Laboratoire Analyse et Environnement pour la Biologie et l'Environnement, Bâtiment Maupertuis, Boulevard François Mitterrand, 91025 Evry Cedex, France

4 CNRS - UMR 8587

\begin{abstract}
The gas-phase interactions between $\mathrm{Ca}^{2+}$ and cysteine (Cys) have been investigated through the use of electrospray mass spectrometry techniques and B3LYP/6-311++G(3df,2p)//B3LYP/6-311+G(d,p) density functional theory computations. The unimolecular decomposition of collision-activated $[\mathrm{Ca}(\mathrm{Cys})]^{2+}$ is dominated by the loss of ammonia, a Coulomb explosion yielding $\mathrm{NH}_{4}{ }^{+}$and $\left[\mathrm{CaC}_{3} \mathrm{H}_{3} \mathrm{O}_{2} \mathrm{~S}\right]^{+}$and the loss of $\mathrm{H}_{2} \mathrm{~S}$. The detection of lighter $\left[\mathrm{C}_{3} \mathrm{H}_{3} \mathrm{OS}\right]^{+}$monocations indicates that the $\left[\mathrm{CaC}_{3} \mathrm{H}_{4} \mathrm{O}_{2} \mathrm{~S}\right]^{2+}$ doubly charged species produced by the loss of ammonia, undergo a subsequent Coulomb explosion yielding $\left[\mathrm{C}_{3} \mathrm{H}_{3} \mathrm{OS}\right]^{+}+\mathrm{CaOH}^{+}$. This $\left[\mathrm{C}_{3} \mathrm{H}_{3} \mathrm{OS}\right]^{+}$cation would finally decompose into $\left[\mathrm{C}_{2} \mathrm{H}_{3} \mathrm{~S}\right]^{+}+\mathrm{CO}$. Alternatively, the aforementioned $\left[\mathrm{CaC}_{3} \mathrm{H}_{4} \mathrm{O}_{2} \mathrm{~S}\right]^{2+}$ dications may also lead to lighter $\left[\mathrm{CaCO}_{2}\right]^{2+}$ and $\left[\mathrm{CaC}_{2} \mathrm{H}_{4} \mathrm{~S}\right]^{2+}$ dications by the loss of $\mathrm{C}_{2} \mathrm{H}_{4} \mathrm{~S}$ and $\mathrm{CO}_{2}$, respectively. A detailed theoretical exploration of the $\mathrm{Ca}^{2+} / \mathrm{Cys}$ potential energy surface indicates that the salt-bridge structures, in which the metal dication interacts with the carboxylate group of the zwitterionic form of cysteine, are at the origin of the different reaction pathways leading to the observed product ions, even though they lie higher in energy than the charge-solvated adduct in which the metal interacts simultaneously with the carbonyl oxygen, the amino and the SH group of its canonical form. The interaction between the metal cation and the base is essentially electrostatic, the calculated binding
\end{abstract}


energy being $560 \mathrm{~kJ} \mathrm{~mol}^{-1}$.

\section{Introduction}

Among the natural aminoacids, cysteine (Cys) presents some interesting peculiarities because, together with methionine, are the only ones which contain sulfur in their composition. The sulfur site is believed to play a crucial role on its complexation with metals, in particular with toxic metals. Actually, Cys seems to reduce the cadmium-induced hepatic and renal toxicity. ${ }^{[1]}$ Besides, some algae are able to counterbalance the excess of toxic metal ions, such as $\mathrm{Pb}^{2+}, \mathrm{Cd}^{2+}, \mathrm{Cu}^{2+}, \mathrm{Zn}^{2+}$ and $\mathrm{Hg}$, by synthesizing phytochelatins, which are peptides rich in Cys. ${ }^{[2]}$ In general, it can be asserted that the interactions of Cys with other multiply-charged metal cations, namely $\mathrm{Fe}, \mathrm{Co}, \mathrm{Zn}$, $\mathrm{Cd},{ }^{[3]}$ have also a large importance in biology. At the same time its $\mathrm{S}-\mathrm{H}$ group can be easily oxidized to yield the so called cystine in which two Cys moieties are attached to each other by a disulfide bond. ${ }^{[4]}$ On the other hand, Cys can also act as a protector again induced radiation damage, ${ }^{[5]}$ and it plays a significant role in energy conversion processes through electron transfer mechanisms. ${ }^{[6]}$ It is also well established that metal ions trigger a large variety of processes in the living beings. For the particular case of Cys, metal cation binding drastically decreases $\mathrm{Cys}^{\prime} \mathrm{pK}_{\mathrm{a}}$, thus facilitating the change of the thiol into a thiolate group. ${ }^{[7]} \mathrm{Ca}^{2+}$ also has a very rich biochemical activity, and it is engaged in many phenomena in the physiological medium. It contributes, for instance, to enhance the base-pair dissociation energy, ${ }^{[8]}$ catalyzes the proton transfer between guanine and cytosine, ${ }^{[8]}$ triggers an assisted intramolecular proton transfer in uracil dimers, ${ }^{[9]}$ participates in the regulation of muscle contraction, ${ }^{[10]}$ or in the thermal stabilization of proteins, and increases the melting temperature of the DNA double helix. ${ }^{[11]}$ Additionally, the gas-phase doubly charged species usually present many peculiarities derived from the fact that they may be metastable with respect to their fragmentation in two monocations in a typical Coulomb explosion. D. Schroeder has dedicated particular attention to this question and some of his papers were seminal in this particular field. ${ }^{[12]}$ For all the aforementioned reasons, it is of relevance to have a clear idea of the reactions that the 
association of $\mathrm{Ca}^{2+}$ can trigger in Cys. In particular, the possible competition between Coulomb explosions, which were found to be dominant for other smaller aminoacids, ${ }^{[13]}$ and fragmentations in which new lighter doubly-charged species are formed through the loss of neutral fragments. Hence the main goal of the present paper is the study of the gas-phase reactions between Cys and $\mathrm{Ca}^{2+}$ through the combination of electrospray ionization/mass spectrometry techniques and density functional theory calculations, which would allow to unambiguously identify the different products detected in collision induced dissociation processes and to propose suitable reaction mechanisms accounting for the observed unimolecular reactivity.

\section{Experimental Section}

Electrospray mass spectra were recorded on a QSTAR PULSAR i (Applied Biosystems/MDS Sciex) hybrid instrument (QqTOF) fitted with a nanospray source. Typically, $6 \mu \mathrm{L}$ of aqueous mixtures of calcium chloride $\left(10^{-3} \mathrm{~mol} \mathrm{~L}^{-1}\right)$ and Cys $\left(10^{-3} \mathrm{~mol} \mathrm{~L}^{-1}\right)$ were nanosprayed $(20-50 \mathrm{~nL}$ $\min ^{-1}$ ) using borosilicate emitters (Proxeon). Samples were ionized by using a $900 \mathrm{~V}$ nanospray needle voltage and the lowest possible nebulizing gas pressure (tens of millibars). The declustering potential (DP, also known as "cone voltage"), defined as the difference in potentials between the orifice plate and the skimmer (grounded), ranged from 0 to $30 \mathrm{~V}$. To improve ion transmission and subsequently sensitivity during the experiments, collision gas $\left(\mathrm{N}_{2}\right)$ was present at all times for collisional focusing in both the Q0 (ion guide preceding Q1 and located just after the skimmer) and Q2 (collision cell) sectors.

For MS/MS spectra, complexes of interest were mass selected using Q1, and allowed to collide with nitrogen as collision gas in the second quadrupole $(\mathrm{Q} 2)$, the resulting fragment ions being analyzed by the time-of-flight (TOF) after orthogonal injection. Furthermore, MS/MS spectra were systematically recorded at various collision energies ranging from $7 \mathrm{eV}$ to to $14 \mathrm{eV}$ in the laboratory frame (the collision energy is given by the difference between the potentials of Q0 and Q2). The CAD parameter, which controls the amount of $\mathrm{N}_{2}$ introduced into $\mathrm{Q} 2$, was set to its minimum value 
in order to limit multiple ion-molecule collisions. Note that, as discussed in previous papers, MS/MS spectra are very likely obtained under multiple-collision regime. ${ }^{[14]}$

Cysteine and calcium chloride were purchased from Aldrich and used without further purification. All experiments were performed in Milli-Q purified water.

\section{Computational Details}

Density functional theory (DFT) calculations were performed by using the Gaussian09 [29] series of programs. ${ }^{[15]}$ Taking into account that Cys is conformationally very rich, the Avogadro 1.0.0 suite of programs ${ }^{[16]}$ was used to built up initial geometries. Among the great variety of functionals available, we have chosen the B3LYP hybrid approach ${ }^{[17]}$ since it has been found to be particularly well suited for the description of $\mathrm{Ca}^{2+}$ complexes, and provides also good results when dealing with the interactions of other aminoacids and $\mathrm{Ca}^{2+} \cdot[13,18]$ The geometries of the different stationary points on the $\mathrm{Ca} / \mathrm{Cys}^{2+}$ potential energy surface (PES) were optimized by using a $6-311+\mathrm{G}(\mathrm{d}, \mathrm{p})$ basis set. Harmonic vibrational frequencies were computed, at the same level, to classify stationary points as local minima or transition structures (TS), and to estimate the zero-point vibrational energy (ZPVE) corrections. To better compare with the experimental observations, the enthalpies of the processes investigated were obtained after adding to the total energies the translational, rotational and vibrational thermal corrections calculated at $298.2 \mathrm{~K}$. Intrinsic reaction coordinate (IRC) computations were used to confirm the connectivity between the located transition states and their adjacent minima. In order to increase the accuracy of our total and relative energies, single point calculations have been carried out by using a more flexible $6-311++\mathrm{G}(3 \mathrm{df}, 2 \mathrm{p})$ basis set.

In order to gain some insight in the bonding between $\mathrm{Ca}^{2+}$ and $\mathrm{Cys}$ we have used two different approaches, namely the atoms in molecules (AIM) theory ${ }^{[19]}$ and the electron localization function (ELF) theory ${ }^{[20]}$. The former is based on a topological analysis of the electron density which permits to define the molecular graph, as the ensemble of local maxima of the density (at the nuclei), the first order saddle points, usually named, bond critical points (BCPs), and the lines of zero gradient 
of the density, or bond paths, connecting them. The ELF approach permits to divide the molecular space in basins associated with the probability of finding bonding electron pairs (disynaptic basins), as well as core or lone-pairs (monosynaptic basins), whose electron population provides useful information about bonding. The molecular graphs and the plots of the energy density, within the framework of the AIM theory were obtained by means of the AIMAll code. ${ }^{[21]}$ The ELF plots were obtained by using the TopMod package. ${ }^{[22]}$

\section{Results and Discusion}

\subsection{Mass spectrometry experiments}

A typical positive-ion nanospray spectrum of an equimolar aqueous mixture $\left(10^{-3} \mathrm{M}\right)$ of calcium chloride and cysteine is presented in Figure 1a. This particular spectrum was obtained at DP=0 V, which corresponds to the mildest source/interface conditions. This spectrum is dominated by a peak detected at $\mathrm{m} / z, 122.02$ which corresponds to protonated cysteine. This is not surprising given the rather high proton affinity of this aminoacid as compared to that of water. ${ }^{[23]}$

Apart from protonated cysteine, several series of calcium-containing species can be observed. The first one corresponds to hydrated calcium dications $\left[\mathrm{Ca}\left(\mathrm{H}_{2} \mathrm{O}\right)_{n}\right]^{2+}(\mathrm{n}=2,3)$, detected at, 37.99 and 46.99, respectively. Their intensity is generally significant at very low DP. Presently, their small abundance is imparted to the very favorable protonation process of the aminoacid. Calcium hydroxide $(\mathrm{m} / \mathrm{z}$ 56.97) is also detected but remains weak over the all range of DP values considered. In addition, doubly-charged complexes of general formula $\left[\mathrm{Ca}(\mathrm{Cys})_{\mathrm{p}}\right]^{2+}(\mathrm{p}=1-2)$ are also observed with a significant intensity, at $m / z, 80.49$ and 141.101 , respectively. A hydrated $\left[\mathrm{Ca}(\mathrm{Cys}) \cdot \mathrm{H}_{2} \mathrm{O}\right]^{2+}$ ion is also detected at $m / z$ 89.50. The abundance of the $[\mathrm{Ca}(\mathrm{Cys})]^{2+}$ ion $(\mathrm{m} / \mathrm{z}$ 80.49) is maximum for $\mathrm{DP}=0 \mathrm{~V}$. Increasing the DP value results in the fast removal of the doubly-charged complexes by "in source" fragmentation processes. At high DP values, the spectrum is dominated by the cysteine immonium ion $(\mathrm{m} / \mathrm{z}, 76.02)$, resulting from the loss of $46 \mathrm{u}$ from the protonated cysteine. Such fragmentation is typical of protonated aminoacids. However, it is worth noting from Figure 1a that 
"in-source" fragmentation already occurs at the lowest DP. The elimination of 46uma is already observed, together with deamination of protonated cysteine $(\mathrm{m} / \mathrm{z}, 105.00)$ and other in source fragment ions coming from the doubly-charged $[\mathrm{Ca}(\mathrm{Cys})]^{2+}$ ion (vide infra). Finally, a singly charged complex of general formula $[\mathrm{Ca}(\mathrm{Cys})-\mathrm{H}]^{+}$is also detected, albeit in weak abundance.

We set the DP parameter to $0 \mathrm{~V}$ to record the MS/MS spectra of the $[\mathrm{Ca}(\mathrm{Cys})]^{2+}$ complex, the CAD parameter being set to its minimum value (1). On our instrument and for this particular system, the smallest collision energy in the laboratory frame $\left(\mathrm{E}_{\text {lab }}\right)$ for which sufficient amount of fragment ions can reach the detector, was $7 \mathrm{eV}$, and at this value dissociation of the precursor ions already readily occurs. $\mathrm{E}_{\text {lab }}$ was scanned from 7 to $14 \mathrm{eV}, \mathrm{N}_{2}$ being used as target gas. This corresponds, for the doubly-charged complex $[\mathrm{Ca}(\mathrm{Cys})]^{2+}$, to center-of-mass collision energies $\left(\mathrm{E}_{\mathrm{CM}}\right)$ ranging from 2.07 to $4.15 \mathrm{eV}$. The CID spectrum obtained at $10 \mathrm{eV}$ (laboratory frame) is given in Figure $1 \mathrm{~b}$. It turns out that the unimolecular reactivity upon collision of the $[\mathrm{Ca}(\mathrm{Cys})]^{2+}$ ion differs markedly from what we observed for the $[\mathrm{Ca}(\text { Glycine })]^{2+}$ ion since with cysteine, the CID spectrum exhibits much more fragment ions. ${ }^{[13]}$ As shown in this picture, the MS/MS spectrum is characterized by a very abundant ion detected at $\mathrm{m} / \mathrm{z}$ 71.98, which corresponds to the elimination of ammonia. The second doubly charged fragment ion observed is detected at $\mathrm{m} / \mathrm{z} 63.50$ and is associated with the elimination of hydrogen sulfide $\left(\mathrm{H}_{2} \mathrm{~S}\right)$. It is worth noting that ammonia loss has been observed with glycine, but only to a very minor extent. Finally, the last dissociation channel involving the initial complex is a charge separation process, leading to two singly charged ions, namely $\mathrm{m} / \mathrm{z}, 18.03$ and 142.95, that can be attributed to $\mathrm{NH}_{4}^{+}$and $\left[\mathrm{Ca}\left(\mathrm{C}_{3}, \mathrm{H}_{3}, \mathrm{O}_{2}, \mathrm{~S}\right)\right]^{+}$, respectively. Examination of the remaining $\mathrm{m} / \mathrm{z}$ ratios indicates that these fragment ions arise from secondary dissociation processes. In order to get more insights about the dissociation sequence, we increased the DP parameter so as to induce fragmentation within the ESI interface. This allowed MS/MS spectra of the fragment ions to be recorded. From this set of experiments the dissociation scheme displayed in Figure 1b could be deduced. The two first ones correspond to elimination of two neutral moieties, namely $\mathrm{CO}_{2}$ and $\mathrm{C}_{2} \mathrm{H}_{4} \mathrm{~S}$, leading to $\mathrm{m} / z 49.98$ and 41.97 , respectively. The third process is a Coulomb explosion, 
giving rise to two singly charged fragments, namely calcium hydroxide $(\mathrm{m} / \mathrm{z} 56.96)$ and $\left[\mathrm{C}_{3}, \mathrm{H}_{3}, \mathrm{O}, \mathrm{S}\right]^{+}(\mathrm{m} / \mathrm{z}, 86.99)$.
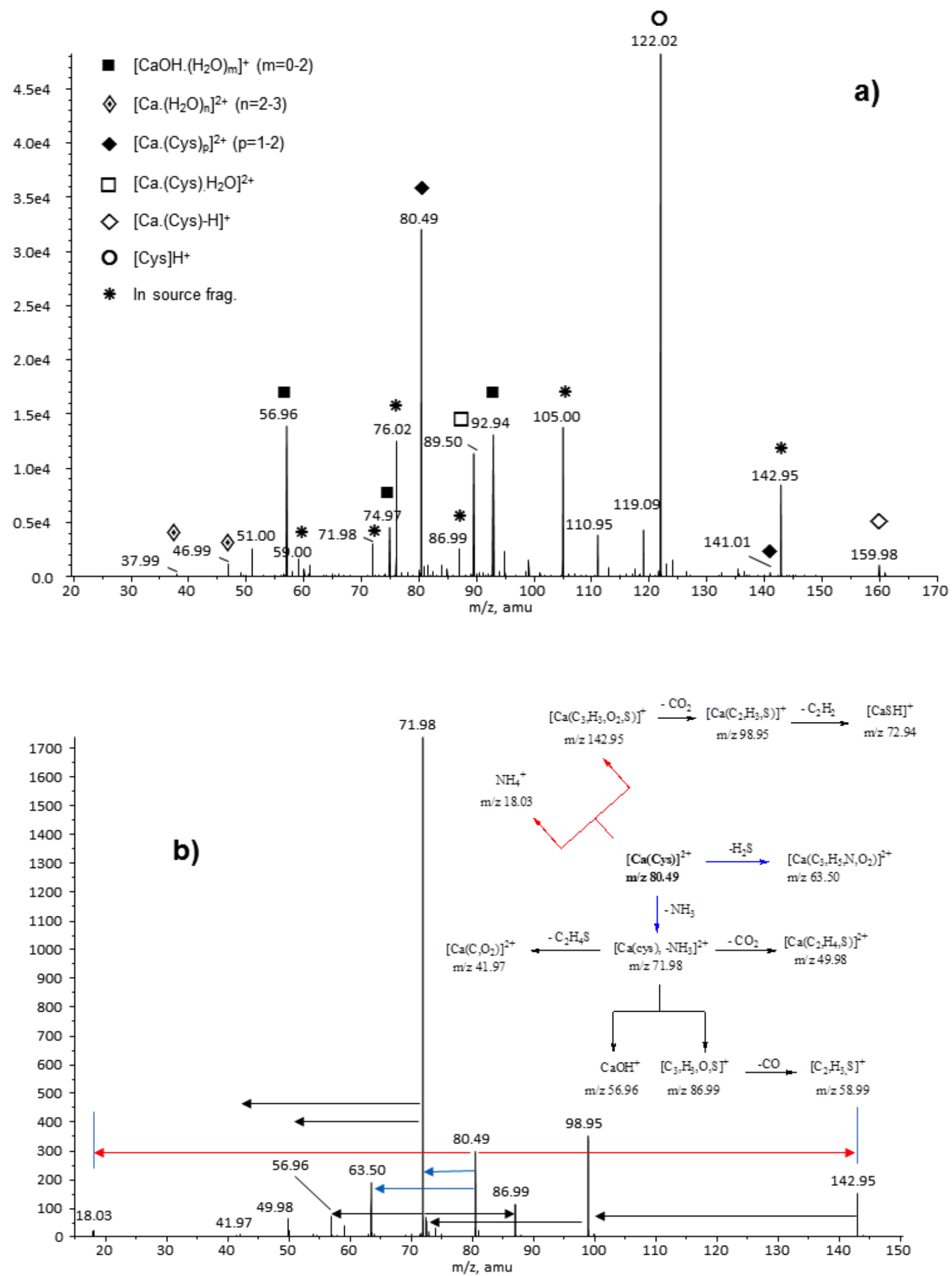
Figure 1. a) Positive-ion nanospray spectrum of an equimolar aqueous mixture $\left(10^{-3} \mathrm{M}\right)$ of calcium chloride and cysteine and b) low-energy MS/MS spectrum of the $[\mathrm{Ca}(\mathrm{Cys})]^{2+}$ complex $(\mathrm{m} / \mathrm{z} 80.49)$ recorded at a collision energy of $10 \mathrm{eV}$ (laboratory frame).

In turn, this latter species expels a $\mathrm{CO}$ molecule to lead ultimately to $\left[\mathrm{C}_{2}, \mathrm{H}_{3}, \mathrm{~S}\right]^{+}(\mathrm{m} / z, 58.99)$. Finally, the last abundant fragment detected $(\mathrm{m} / \mathrm{z}$ 98.95) originates from $\mathrm{m} / z 142.95$ through loss of carbon dioxide. Its MS/MS spectrum is characterized by a single process corresponding to the elimination of acetylene and the formation of $\mathrm{CaSH}^{+}(\mathrm{m} / \mathrm{z}, 72.94)$.

To summarize, although less studied experimentally than monocations, the interaction of divalent ions seems to result in numerous fragment ions upon CID, as attested by the present report and by a previous study dealing with Co(II) complexes. ${ }^{[3 i]}$ The unimolecular reactivity upon collision of the $[\mathrm{Ca}(\mathrm{Cys})]^{2+}$ complex is much richer than the one observed with monocations and notably alkali metals. Recent threshold collision induced dissociation studies have shown that $\mathrm{M}^{+}$-cysteine complexes $(\mathrm{M}=\mathrm{Na}, \mathrm{K}, \mathrm{Rb}, \mathrm{Cs})$ react solely by loss of the intact cysteine, ${ }^{[24]}$ while lithiated cysteine also dissociates by deamination. ${ }^{[24 a, 25]}$ Finally, the behavior of the $[\mathrm{Ca}(\mathrm{Cys})]^{2+}$ and $[\mathrm{Ca}(\mathrm{Gly})]^{2+}$ complexes upon collision are markedly different, the latter leading to abundant calcium hydroxide and immonium ion through two-step processes. ${ }^{[13]}$ Such dissociation processes are not encountered with cysteine.

\subsection{Structure, stability and bonding of $[\mathrm{Ca}(\mathrm{Cys})]^{2^{+}}$complexes}

As it was reported before, ${ }^{[26]}$ the most stable $[\mathrm{Ca}(\mathrm{Cys})]^{2^{+}}$adduct corresponds to a charge-solvated structure, $\boldsymbol{a}$, in which the metal dication appears tri-coordinated to the carbonyl oxygen, the amino nitrogen and the sulfur atom of the S-H group of the canonical form of the aminoacid (see Figure $2)$, similarly to what has been found before for the $[\mathrm{Ca}(\text { serine })]^{2^{+}}$complex. ${ }^{[27]}$ 


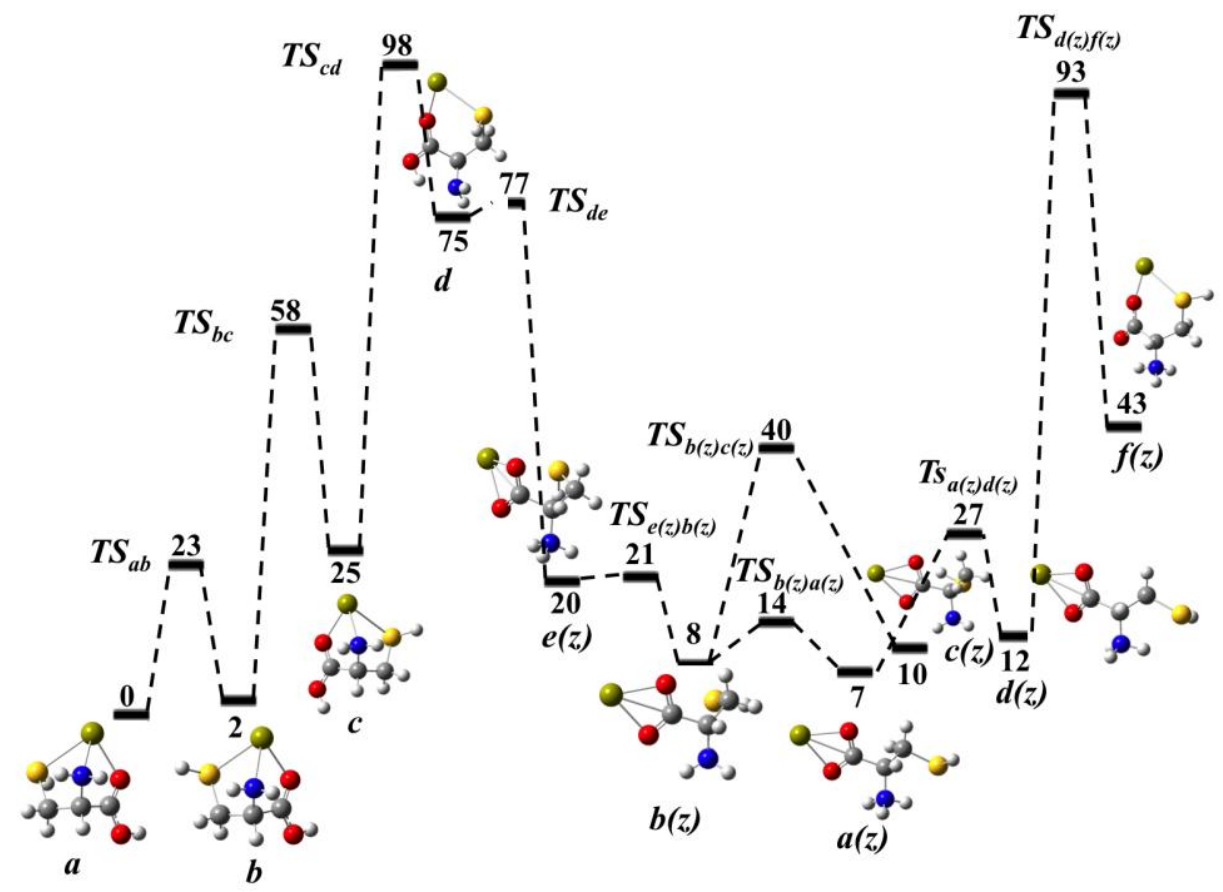

Figure 2. Enthalpy profiles connecting the most stable $\mathrm{Ca}^{2+}$ adducts to the canonical $(\boldsymbol{a}-\boldsymbol{d})$ and the zwitterionic $(\boldsymbol{a}(\boldsymbol{z})-\boldsymbol{f}(\boldsymbol{z}))$ forms of cysteine. Relative enthalpies calculated at B3LYP/6$311++\mathrm{G}(3 \mathrm{df}, 2 \mathrm{p}) / / \mathrm{B} 3 \mathrm{LYP} / 6-311+\mathrm{G}^{* *}$ level of theory at $298.2 \mathrm{~K}$, are in $\mathrm{kJ} \mathrm{mol}^{-1}$

Slightly higher in energy there is a similar structure, $\boldsymbol{b}$, which differs from the previous one by the relative orientation of the $\mathrm{S}-\mathrm{H}$ group. A further internal rotation of the $\mathrm{OH}$ group leads to a third local minimum, $\boldsymbol{c}$, which lies $25 \mathrm{~kJ} \mathrm{~mol}^{-1}$ above the global minimum. A more demanding conformational process leads to the breaking of the $\mathrm{Ca}-\mathrm{NH}_{2}$ interaction, through the transition state $\boldsymbol{T S} \boldsymbol{S}_{\boldsymbol{c}}$, yielding complex $\boldsymbol{d}$, which has an arrangement that favors a proton transfer from the $\mathrm{OH}$ group, through a very low activation barrier, towards the amino group producing a salt-bridge complex, $\boldsymbol{e}(z)$, in which the metal dication interacts with a zwitterionic form of Cys. In what follows, we will name these kinds of complexes in alphabetic order, starting from the most stable, but adding $(z)$ to indicate that they involve a zwitterionic form of the aminoacid. An isomerization of structure $\boldsymbol{e}(z)$ yields $\boldsymbol{a}(\boldsymbol{z})$ and $\boldsymbol{b}(z)$, which are almost degenerate and only 7 and $8 \mathrm{~kJ} \mathrm{~mol}^{-1}$, higher than the global minimum, respectively. These salt-bridge structures are connected with other two local minima, $\boldsymbol{c}(z)$ and $\boldsymbol{d}(z), 10$ and $12 \mathrm{~kJ} \mathrm{~mol}^{-1}$, above the global minimum, respectively. It should 
be noted that in all the $\boldsymbol{a}(\boldsymbol{z})-\boldsymbol{e}(\boldsymbol{z})$ complexes the metal dication forms a bridge between the two oxygen atoms of carboxylate group of the zwitterionic form of Cys (see Figure 2).

A mixture of charge-solvated and zwitterionic forms should be present in our instrument. As a matter of fact, although the canonical form of cysteine is predicted to be $15 \mathrm{~kJ} \mathrm{~mol}^{-1}$ lower in energy than its zwitterionic counterpart in the gas-phase, in aqueous solution, using a polarized continuous model (PCM) the latter is predicted to be $65 \mathrm{~kJ} \mathrm{~mol}^{-1}$ more stable than the former. Hence, taking into account that during our experiments gaseous ions are generated by electrospray ionization from aqueous solutions, a large presence of $\mathbf{a}(\mathbf{z})-\mathbf{f}(\mathbf{z})$ complexes should be expected together with charged-solvated species. As shown in Figure 2, the isomerization to go from charge solvated structures to salt bridge ones proceeds through a barrier of $98 \mathrm{~kJ} \mathrm{~mol}^{-1}$. In presence of solvent, lowering of this isomerization barrier through water-assisted mechanisms cannot be excluded. In addition, this activation barrier can also be easily crossed during the collisional activation process occurring within Q2, given the center of mass collision energies used during experiments. Consequently, the formation of both types of structures during our experiments appears very likely. It is also worth noting that structures $\boldsymbol{a}, \boldsymbol{b}, \boldsymbol{d}, \boldsymbol{a}(\boldsymbol{z})$ and $\boldsymbol{c}(z)$ were also found to be local minima on the PES when the interaction involves alkali metal ions, structure $\boldsymbol{a}$ being also the global minimum. However, the relative energies for these structures for $\mathrm{Ca}^{2+}$ are at variance with respect to those calculated for alkali metal ions, in particular for $\mathrm{Li}^{+}$. Also, the interactions with doubly-charged transition metal ions, namely $\mathrm{Zn}^{2+}, \mathrm{Cd}^{2+}$ and $\mathrm{Hg}^{2+}$ yield as the most stable structure complex $\boldsymbol{a}$. Conversely, for $\mathrm{Cu}^{2+}$ complex $\boldsymbol{a}$ is not the global minimum as it lies $7.1 \mathrm{~kJ} \mathrm{~mol}^{-1}$ higher in energy than the complex shown in scheme 1. This is also at variance with the behavior of Cys with respect to $\mathrm{Ca}^{2+}$ because this structure, although a local minimum of the PES, lies $139 \mathrm{~kJ} \mathrm{~mol}^{-1}$ higher in energy than the global minimum $\boldsymbol{a}$. 


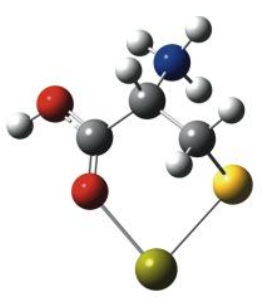

Scheme 1. The most stable $[\mathrm{Cu}(\mathrm{Cys})]^{2+}$ complex becomes $139 \mathrm{~kJ} \mathrm{~mol}^{-1}$ less stable than structure $\boldsymbol{a}$ when $\mathrm{Cu}^{2+}$ is replaced by $\mathrm{Ca}^{2+}$.

The calculated cysteine-Ca ${ }^{2+}$ binding energy $\left(560 \mathrm{~kJ} \mathrm{~mol}^{-1}\right)$ is significantly higher than that exhibited by urea $\left(453 \mathrm{~kJ} \mathrm{~mol}^{-1}\right)$ and also higher than that calculated for glycine $\left(516 \mathrm{~kJ} \mathrm{~mol}^{-1}\right)$. This finding is in line with the different bonding patterns in these systems. While with Cysteine $\mathrm{Ca}^{2+}$ appears, as mentioned above, tri-coordinated, within urea/ $\mathrm{Ca}^{2+}$ global minimum $\mathrm{Ca}^{2+}$ is monocoordinated to the carbonyl oxygen, whereas with glycine $\mathrm{Ca}^{2+}$ is di-coordinated to the carboxylate group of glycine's zwitterionic form. Indeed, an analysis of the electron density of the global minimum $\boldsymbol{a}$, shows the existence of BCPs between the metal and the three basic sites of the aminoacid as well as the existence of a cage critical point (see Figure 3a). Also coherently, three disynaptic basins $\mathrm{V}(\mathrm{Ca}, \mathrm{O}), \mathrm{V}(\mathrm{Ca}, \mathrm{N})$ and $\mathrm{V}(\mathrm{Ca}, \mathrm{S})$ appear in the corresponding ELF (see Figure $3 \mathrm{~b}$ ). Note however that the population of the core of calcium is very close to $18 \mathrm{e}$-, ratifying that no significant charge transfer occurs from Cys towards $\mathrm{Ca}^{2+}$. This clear electrostatic nature of the cysteine-Ca ${ }^{2+}$ interaction is also viewed in the plots of the energy density which show well-defined positive areas between the basic sites of cysteine and the core of $\mathrm{Ca}^{2+}$ (see Figure $3 \mathrm{c}$ ). 

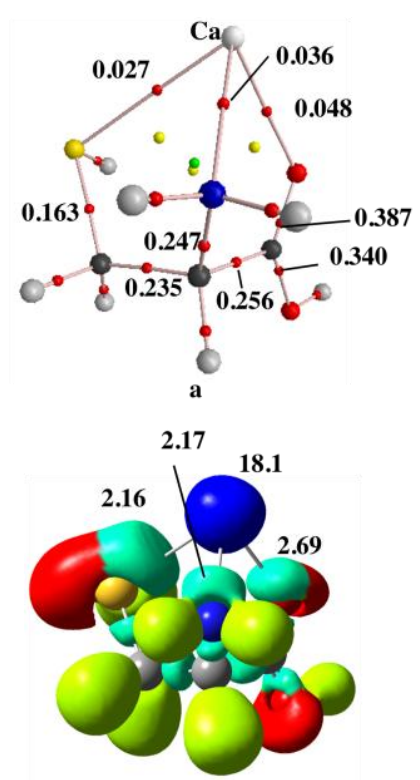
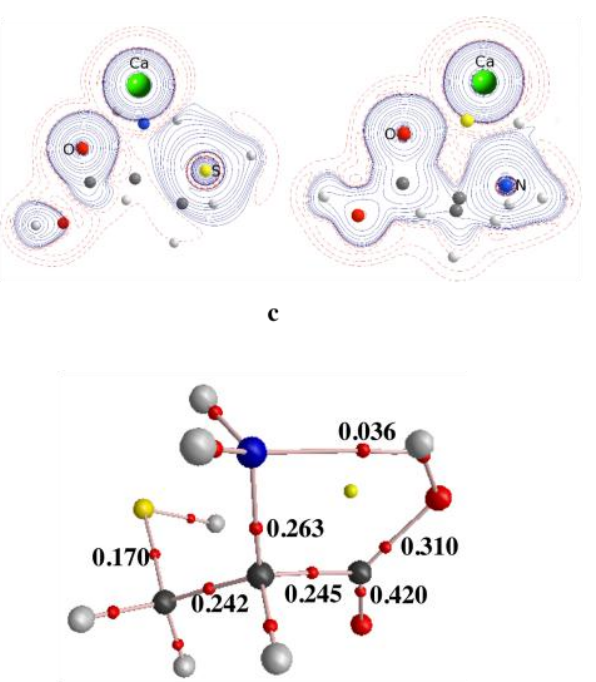

d

Figure 3. Molecular graph (a), ELF (b) and energy density plots (c) for the most stable $[\mathrm{Ca}(\mathrm{Cys})]^{2+}$ adduct. For the sake of comparison the molecular graph of isolated cysteine is shown in (d). The electron densities of the molecular graphs are in a.u. and the populations of the ELF in e-. Dashed red lines and solid blue lines in (c) correspond to positive and negative values of the energy density, respectively.

However, the existence of disynaptic basins involving calcium atom, is a clear indication that although the interaction is essentially electrostatic there are significant polarization effects due to the strong coulombic field created by the metal dication. Indeed, a NBO analysis ${ }^{[28]}$ shows significant second order interaction energies between the empty orbitals of the metal ion and the lone pairs of the $\mathrm{N}, \mathrm{O}$ and $\mathrm{S}$ atoms interacting with it. Consistently, a comparison of the molecular graph of the $[\mathrm{Ca}(\mathrm{Cys})]^{2+}$ complex and that of the isolated Cys (see Figure $4 \mathrm{~d}$ ) shows a significant activation of the three bonds, $\mathrm{C}=\mathrm{O}, \mathrm{C}-\mathrm{N}$ and $\mathrm{C}-\mathrm{S}$ directly interacting with the metal, whose electron densities significantly decrease on going from the isolated aminoacid to the $\mathrm{Ca}^{2+}$ complex. These polarization effects are also transmitted to the $\mathrm{C}-\mathrm{C}-\mathrm{C}$ chain, where the $\mathrm{C}-\mathrm{CO}$ bond reinforces, whereas the C-CS bond weakens. Also simultaneously the $\mathrm{C}-\mathrm{OH}$ bond also reinforces slightly.

It is worth noting that the possibility of tri-coordination in cysteine- $\mathrm{Ca}^{2+}$ complexes explains why the global minimum involves the canonical form of this aminoacid, whereas the complexes in 
which the interaction occurs with the carboxylate group of the zwitterionic form lie higher in energy, at variance with what was found for glycine. This also explains the enhanced binding energy of $\mathrm{Ca}^{2+}$ to cysteine, with respect to glycine.

\subsection{Collision Induced Dissociation mechanisms}

\subsubsection{Loss of Ammonia}

As indicated in previous sections, the dominant peak in the MS/MS spectrum corresponds to a doubly-charged species arising from deamination. Obviously, the most favorable precursors for such fragmentations are complexes $a(z)-f(z)$ in which the metal ion interacts with the carboxylate group of the zwitterionic form of cysteine. In this respect, it should be noted that although the canonical form of cysteine is predicted to be $15 \mathrm{~kJ} \mathrm{~mol}^{+}$lower in energy than its zwitterionic counterpart in the gas phase, in aqueous solution, using a polarized continuous model (PCM) the tatter is predicted to be $65 \mathrm{~kJ} \mathrm{~mol}^{-1}$ more stable than the former. Hence, taking into account that during these experiments gaseous ions are generated by electrospray ionization, a large presence of $\boldsymbol{a}(z)-f(z)$ complexes should be expected. Besides, as shown in Figure 2 the isomerization to go from charge solvated structures to salt bridge ones proceeds through a barrier of $98 \mathrm{~kJ} \mathrm{~mol}^{+}$, so not much of these isomerizations should be expected under normal experimental conditions. A detailed exploration of the mechanisms for the loss of ammonia shows that in all cases this fragmentation implies a certain activation barrier (see Figure 4) which connects the salt-bridge complexes $(\boldsymbol{a}(\boldsymbol{z})$ $f(z))$ with an intermediate in which the $\mathrm{NH}_{3}$ molecule forms a hydrogen bonded complex with the $\left[\mathrm{C}_{3} \mathrm{O}_{2} \mathrm{H}_{3} \mathrm{SCa}\right]^{2+}$ doubly-charged species and which eventually dissociates yielding the $\boldsymbol{P}_{\boldsymbol{1}}-\boldsymbol{P}_{\mathbf{3}}$ doubly-charged products. The mechanisms with origin in $\boldsymbol{a}(\boldsymbol{z})-\boldsymbol{d}(\boldsymbol{z})$ involve rather similar activation barriers around $200 \mathrm{~kJ} \mathrm{~mol}^{-1}$ and lead to $\left[\mathrm{C}_{3} \mathrm{O}_{2} \mathrm{H}_{3} \mathrm{SCa}\right]^{2+}$ products which only differ in the local conformation of the $\mathrm{HC}-\mathrm{CH}_{2}-\mathrm{SH}$ group. It is worth noting, that in principle is also possible to lose $\mathrm{NH}_{3}$ from salt bridge complexes in which is the proton of the $\mathrm{SH}$ group the one that is transferred towards the amino group. However, as shown in Figure S1 of the supporting information, this 
mechanism leads to products which lie much higher in energy than $\boldsymbol{P}_{\mathbf{1}}-\boldsymbol{P}_{\mathbf{3}}$.

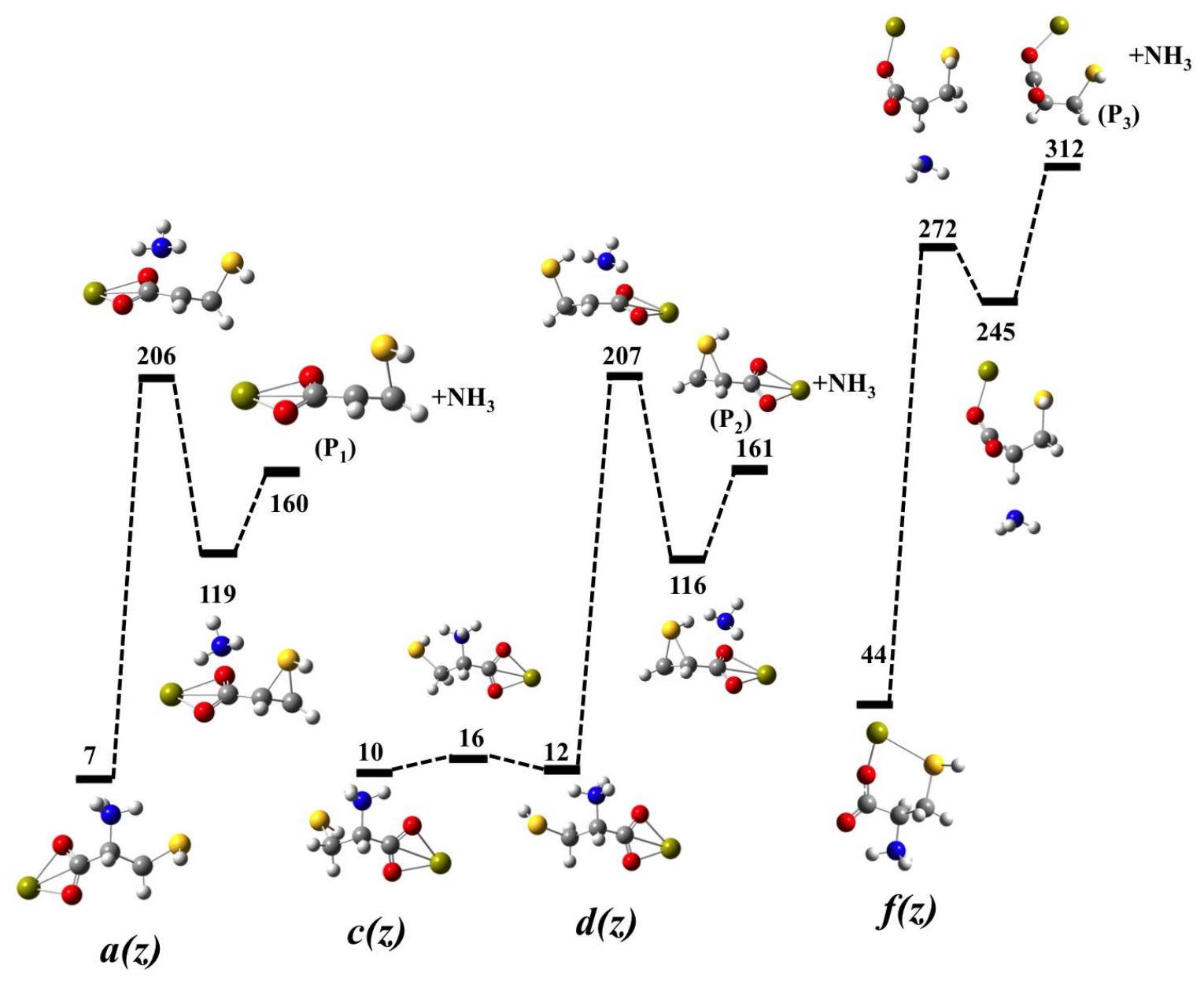

Figure 4. Enthalpy profiles associated with the loss of ammonia from complexes $a(z), \boldsymbol{c}(z)$ and $\boldsymbol{f}(z)$. Relative enthalpies $\left(\mathrm{kJ} \mathrm{mol}^{-1}\right)$ are calculated, with respect to the global minimum $\boldsymbol{a}$, at the B3LYP/6$311++\mathrm{G}(3 \mathrm{df}, 2 \mathrm{p}) / / \mathrm{B} 3 \mathrm{LYP} / 6-311+\mathrm{G}^{* *}$ level of theory at $298.2 \mathrm{~K}$.

\subsubsection{Subsequent fragmentations after the loss of ammonia}

\subsubsection{Formation of $\left[\mathrm{Ca}\left(\mathrm{CO}_{2}\right)\right]^{2+}$}

From the doubly-charged ions produced in the loss of ammonia, the most straightforward process would be the formation of $\left[\mathrm{Ca}\left(\mathrm{CO}_{2}\right)\right]^{2+}$, since this fragmentation implies the direct cleavage of the $\mathrm{HC}-\mathrm{CO}_{2} \mathrm{Ca}$ bond, yielding a linear $\mathrm{OCOCa}^{2+}$ dication and $\mathrm{H}_{2} \mathrm{C}=\mathrm{CH}-\mathrm{SH}$ neutral which lie $216 \mathrm{~kJ}$ $\mathrm{mol}^{-1}$ above $\boldsymbol{P}_{\boldsymbol{l}}$. It should be noted however, that in all cases the departure of $\mathrm{CO}_{2} \mathrm{Ca}^{2+}$ is 
accompanied by an isomerization of the remaining organic residue. As a matter of fact, the breaking of the $\mathrm{CH}-\mathrm{CO}_{2} \mathrm{Ca}$ bond would lead to a $\mathrm{HS}-\mathrm{CH}_{2}-\mathrm{CH}$ fragment. However, a scan of the aforementioned bond cleavage (see Figure S2 of the supporting information) indicates that a simultaneous cleavage of the HS- $\mathrm{CH}_{2}$ bond and the formation of a HS-CH linkage takes place, so that the final structure of the organic subunit is $\mathrm{H}_{2} \mathrm{C}=\mathrm{CH}-\mathrm{SH}$.

\subsubsection{Consecutive loss of $[\mathrm{CaOH}]^{+}$and $\mathrm{CO}$}

The other observed fragmentations, the loss of $[\mathrm{CaOH}]^{+}+\mathrm{CO}$ or the loss of $\mathrm{CO}_{2}$ require necessarily some previous isomerization. For the loss of $[\mathrm{CaOH}]^{+}$prior to the fragmentation of $\boldsymbol{P}_{\boldsymbol{1}}-\boldsymbol{P}_{\mathbf{3}}$ a proton transfer towards one of the oxygen atoms has to take place, to facilitate the subsequent formation of $[\mathrm{CaOH}]^{+}$. Three possible mechanisms can be envisaged depending whether this proton comes from the $\mathrm{CH}_{2}$ group of $\boldsymbol{P}_{\boldsymbol{1}}$ yielding complex $\boldsymbol{P}_{\mathbf{1 z a}}$ (see Figure 5a), the $\mathrm{CH}$ group of $\boldsymbol{P}_{\boldsymbol{1}}$ yielding complex $\boldsymbol{P}_{1 z \boldsymbol{b}}$ (see Figure 5b), or the SH group of $\boldsymbol{P}_{2}$ yielding $\boldsymbol{P}_{2 z}$ (see Figure 5c).

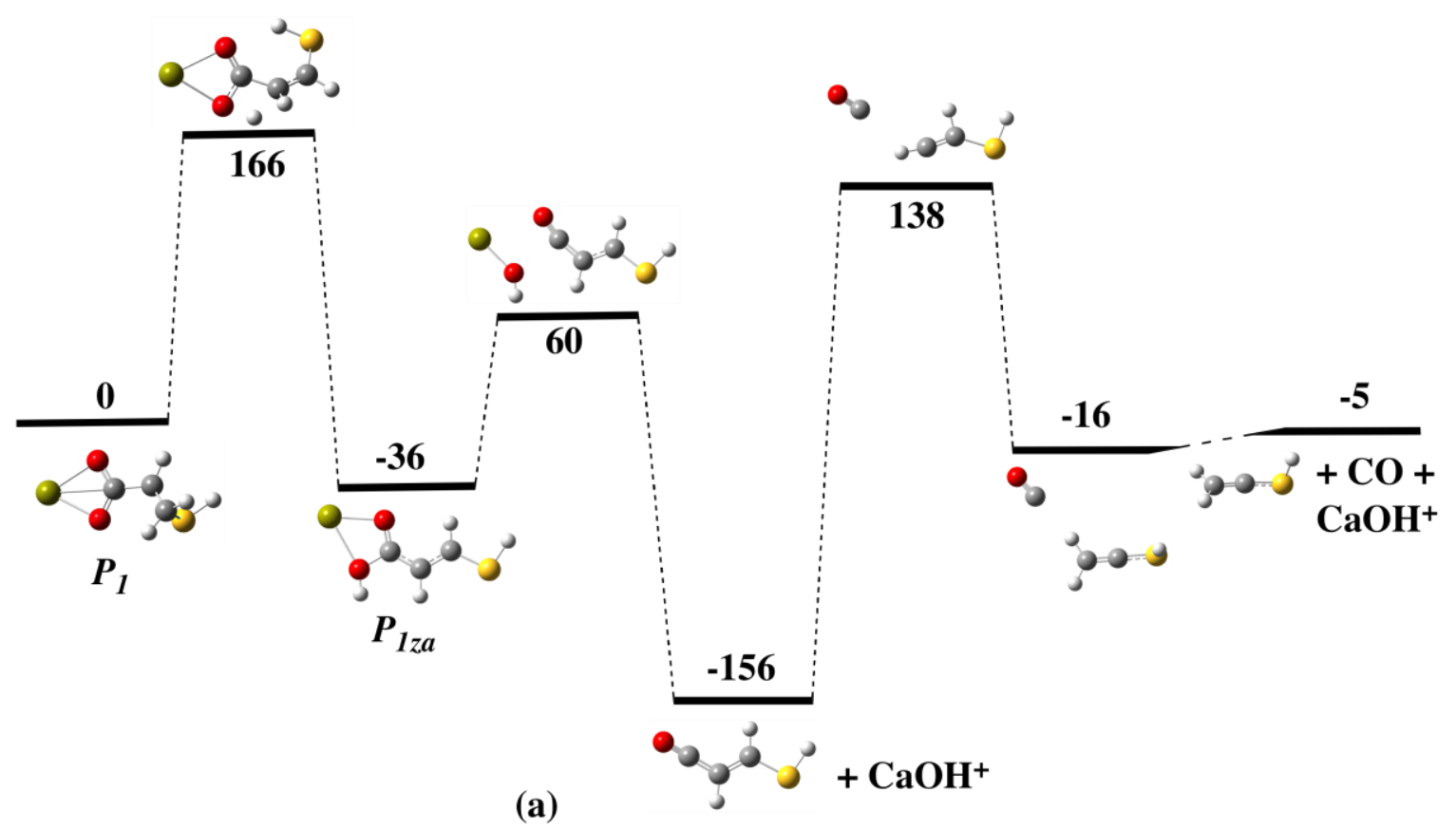




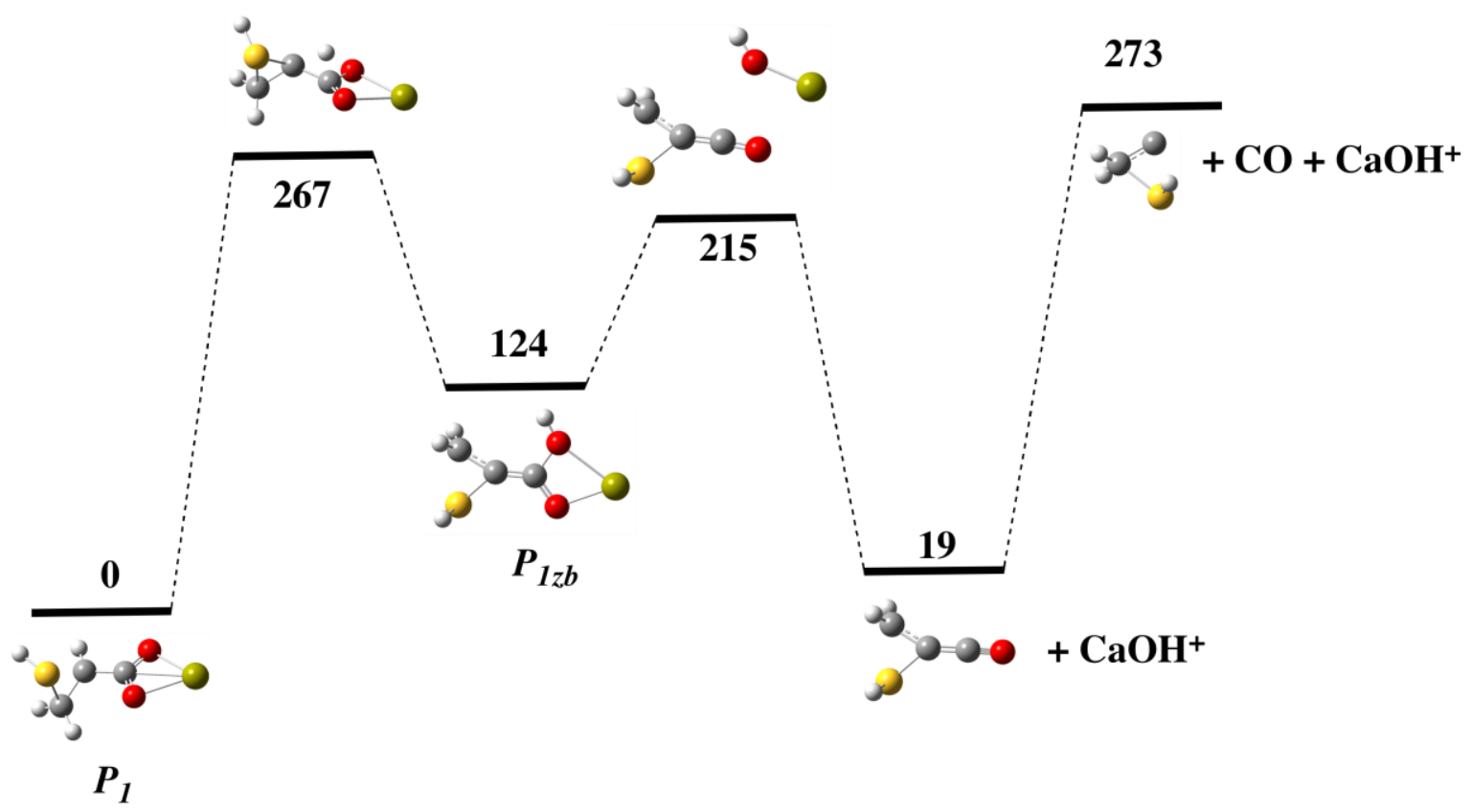

(b)

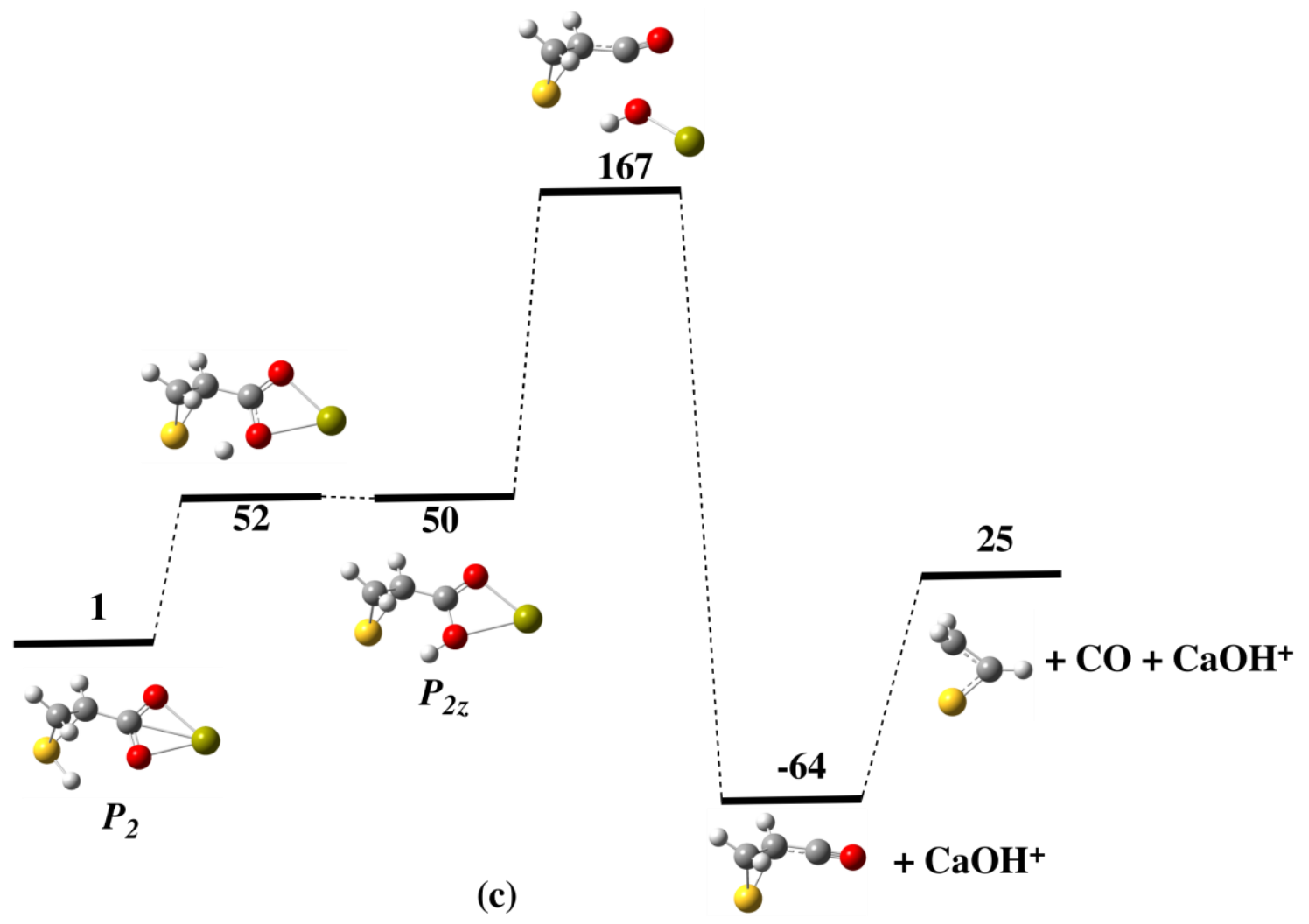

Figure 5. Enthalpy profiles for the successive loss of $\mathrm{CaOH}^{+}$and $\mathrm{CO}$ from the most stable doubly- 
charged ions, $\boldsymbol{P}_{\mathbf{1}}$ and $\boldsymbol{P}_{2}$, produced after the loss of ammonia. Relative enthalpies (in $\mathrm{kJ} \mathrm{mol}^{-1}$ ), calculated at the B3LYP/6-311++G(3df,2p)//B3LYP/6-311+G** level of theory at $298.2 \mathrm{~K}$, are referred to $\boldsymbol{P}_{\boldsymbol{l}}$.

As shown in Figure 5c the conversion of $\boldsymbol{P}_{2}$ to $\boldsymbol{P}_{2 z}$ is the most favorable of the three processes since it involves a much lower activation barrier than the other two. Once $\boldsymbol{P}_{2 z}$ is produced, the formation of $[\mathrm{CaOH}]^{+}$takes place through an additional barrier of $117 \mathrm{~kJ} \mathrm{~mol}^{-1}$ yielding a three-membered cyclic structure which eventually loss $\mathrm{CO}$ to yield as a final product a $\mathrm{CH}_{2}-\mathrm{CH}-\mathrm{S}^{+}$cation. This mechanism should compete however with the one with origin in $\boldsymbol{P}_{\boldsymbol{1}}$ (Figure 5a), because although the barrier connecting $\boldsymbol{P}_{\boldsymbol{1}}$ and $\boldsymbol{P}_{\mathbf{1 z a}}$ is much higher than the one connecting $\boldsymbol{P}_{\mathbf{2}}$ to $\boldsymbol{P}_{2 z}$, is practically equal to that involved in the loss of $[\mathrm{CaOH}]^{+}$from in $\boldsymbol{P}_{2 z}$. The alternative mechanism through the $\boldsymbol{P}_{\boldsymbol{I} \boldsymbol{b}}$ (Figure 5b) is not competitive with the other two, since both steps, the $\boldsymbol{P}_{\boldsymbol{1}}-\boldsymbol{P}_{\boldsymbol{1 z b}}$ isomerization and the posterior loss of $\mathrm{CaOH}^{+}$involve rather high activation barriers. Note that in the mechanism with origin in $\boldsymbol{P}_{\boldsymbol{I}}$ the final loss of CO occurs through an activation barrier of $138 \mathrm{~kJ} \mathrm{~mol}^{-1}$ above the reactant, whereas for the mechanism with origin in $\boldsymbol{P}_{\mathbf{2}}$ the loss of $\mathrm{CO}$ is only thermodynamically controlled. In fact, in the first mechanism the cleavage of the HC-CO bond is accompanied by a simultaneous hydrogen shift from the central $\mathrm{CH}$ group to the terminal one (see Figure $\mathrm{S} 3$ of the supporting information), yielding a $\mathrm{CH}_{2}=\mathrm{C}-\mathrm{SH}^{+}$ion, which lies $30 \mathrm{~kJ} \mathrm{~mol}^{-1}$ lower in energy than $\mathrm{CH}_{2}-\mathrm{CH}-\mathrm{S}^{+}$produced in the second mechanism. In summary, the sequential loss of ammonia, $\mathrm{CaOH}^{+}$and $\mathrm{CO}$, yields two different conformers of the product ion, which are interconnected by an activation barrier of $301 \mathrm{~kJ} \mathrm{~mol}^{-1}$ (see Figure S4 of the supporting information).

\subsubsection{Loss of $\mathrm{CO}_{2}$}

The mechanism associated with the loss of $\mathrm{CO}_{2}$ is necessarily more convoluted, its precursor being a complex $\boldsymbol{P}_{5}$ in which the metal dication bridges between $\mathrm{CO}_{2}$ and thioacetaldehyde, $\mathrm{CH}_{3}-\mathrm{C}(\mathrm{S})-\mathrm{H}$. The most favorable mechanism to reach this complex from the most stable $\boldsymbol{P}_{\boldsymbol{1}}$ doubly-charged species is shown in Figure 6. The first step is the isomerization through a barrier of $172 \mathrm{~kJ} \mathrm{~mol}^{-1}$ of 
$\boldsymbol{P}_{\boldsymbol{1}}$ to reach the $\boldsymbol{P}_{3}$ isomer. Note that $\boldsymbol{P}_{\mathbf{3}}$ can be alternatively produced by the fragmentation of the $\boldsymbol{f}(z)$ complex (see Figure 4). A hydrogen shift from the SH group of $\boldsymbol{P}_{\mathbf{3}}$ to one of the carbonyl oxygens, triggers a simultaneous proton transfer from the $\mathrm{SCH}_{2}$ group towards the $\mathrm{CH}$ one, leading a much more stable $\boldsymbol{P}_{4}$ dication, connected by an internal rotation of its $\mathrm{OH}$ group with the conformer $\boldsymbol{P}_{4 a}$. A proton transfer from its $\mathrm{OH}$ group towards the $\mathrm{CH}_{2}$ group results in the $\mathrm{H}_{2} \mathrm{C}-\mathrm{O}$ bond cleavage and the formation of complex $\boldsymbol{P}_{5}$. From this doubly-charged intermediate, two possible fragmentations are possible depending whether the bond that cleaves is the $\mathrm{S}$-Ca or the OCa. The latter process is the most favorable one from the thermodynamic viewpoint, leading to the loss of $\mathrm{CO}_{2}$, whereas the alternative loss of thioacetaldehyde is found to be $110 \mathrm{~kJ} \mathrm{~mol}^{-1}$ less favorable.

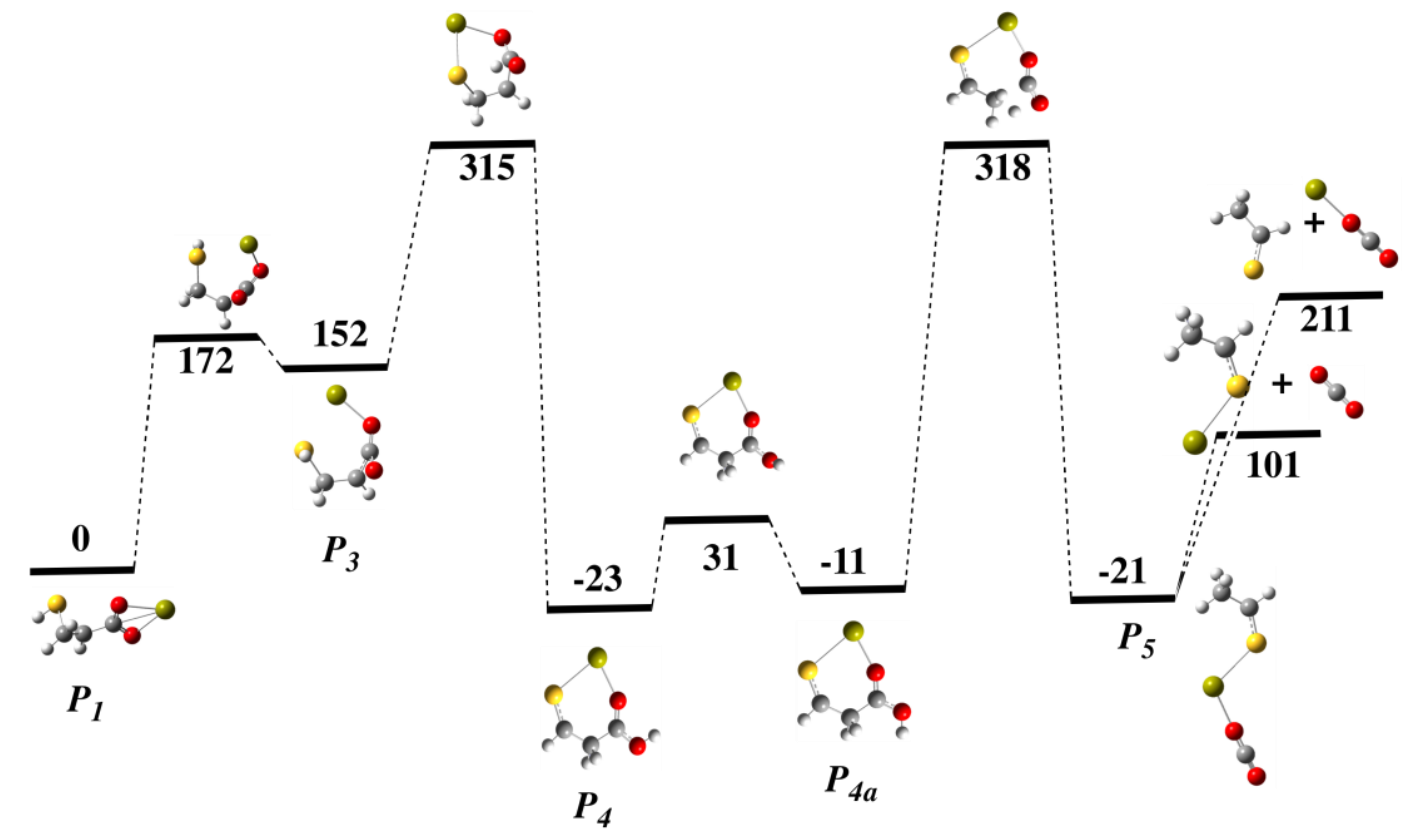

Figure 6. Mechanism associated with the loss of $\mathrm{CO}_{2}$ from the most stable doubly-charged ion, $\boldsymbol{P}_{\boldsymbol{1}}$, produced after the loss of ammonia. Relative enthalpies, calculated at the B3LYP/6$311++\mathrm{G}(3 \mathrm{df}, 2 \mathrm{p}) / / \mathrm{B} 3 \mathrm{LYP} / 6-311+\mathrm{G}^{* *}$ level of theory at $298.2 \mathrm{~K}$, are in $\mathrm{kJ} \mathrm{mol}^{-1}$.

\subsubsection{Loss of $\mathrm{H}_{2} \mathrm{~S}$}

For the sake of simplicity the mechanism for the loss of $\mathrm{H}_{2} \mathrm{~S}$ has been investigated only with origin 
in the most stable salt-bridge complex $\boldsymbol{a}(\boldsymbol{z})$. The first step of the process (see Figure 7) involves an internal rotation around the NC-CS bond yielding a new conformer $\boldsymbol{a}(\boldsymbol{z}) \boldsymbol{1}$ in which the hydrogen shift from the $\mathrm{CH}$ group towards the $\mathrm{SH}$ group is much easier. This hydrogen shift, which involves a further activation barrier of $144 \mathrm{~kJ} \mathrm{~mol}^{-1}$, is followed by a C-S bond cleavage, yielding a complex c1 in which the $\mathrm{H}_{2} \mathrm{~S}$ molecule is hydrogen bonded to the amino group of the $\mathrm{CH}_{2}=\mathrm{C}\left(\mathrm{NH}_{3}\right)-\mathrm{CO}_{2} \mathrm{Ca}^{2+}$ moiety. Consequently, the dissociation of this complex into the product dication $\boldsymbol{P}_{\boldsymbol{s}}$ and a neutral $\mathrm{H}_{2} \mathrm{~S}$ molecule implies an extra energy of $58 \mathrm{~kJ} \mathrm{~mol}^{-1}$. Note that the limiting step of this mechanism involves a barrier $24 \mathrm{~kJ} \mathrm{~mol}^{-1}$ higher than the maximum activation energy calculated for ammonia loss, is consistent with the observed dominant loss of ammonia.

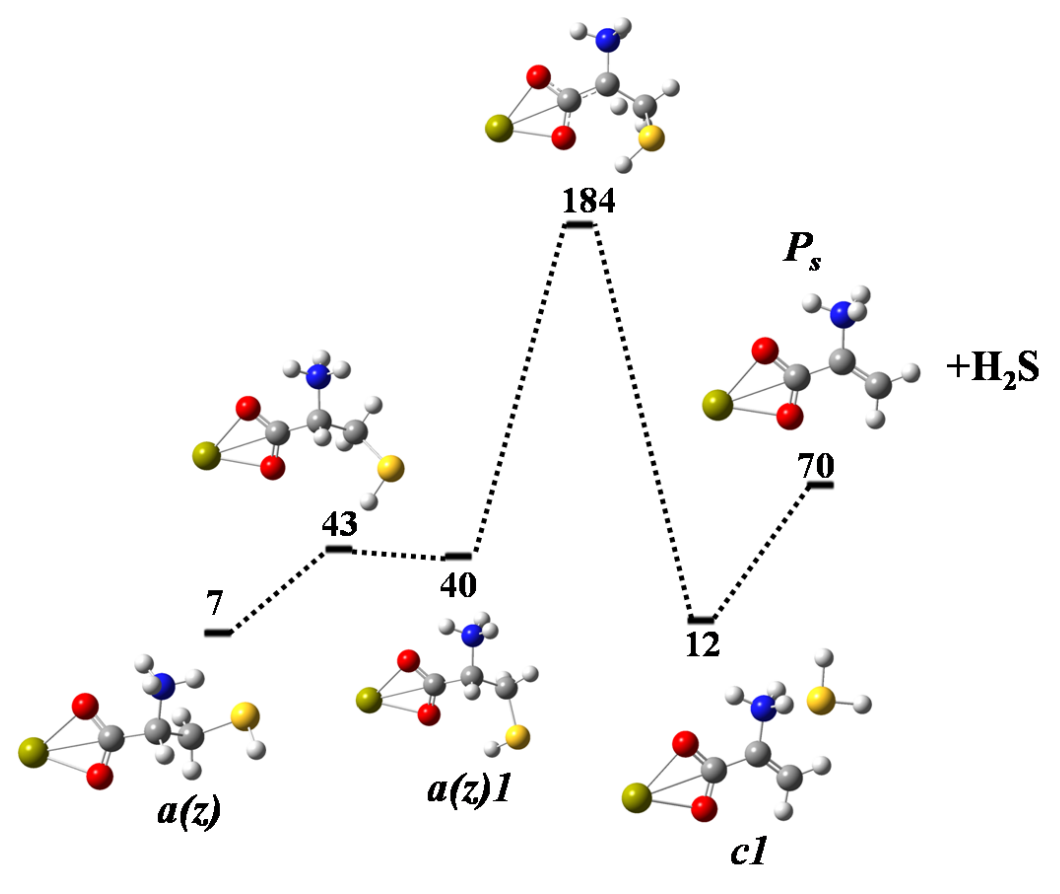

Figure 7. Enthalpy profile associated with the loss of $\mathrm{H}_{2} \mathrm{~S}$. Relative enthalpies $\left(\mathrm{kJ} \mathrm{mol}^{-1}\right)$, calculated at the B3LYP/6-311++G(3df,2p)//B3LYP/6-311+G** level of theory at $298.2 \mathrm{~K}$, are referred to the global minimum $\boldsymbol{a}$ of the potential energy surface.

Although, as mentioned above, it should be expected the salt-bridge complexes to be dominant under electrospray experimental conditions, we have also explored the loss of $\mathrm{H}_{2} \mathrm{~S}$ from the global 
minimum $\boldsymbol{a}$. The corresponding energy profiles are plotted in Figure S5 of the supporting information, showing that the different mechanisms found involve activation barriers significantly higher than those in Figure 7. Similarly, the mechanisms with origin in other salt-bridge structures such as $\boldsymbol{c}(z)$ or $\boldsymbol{f}(z)$ also involve barriers larger than those in Figure 7 Also the possibility of having a 1,2-H shift from the $\mathrm{CH}_{2}$ group towards the $\mathrm{SH}$ one, instead of a 1,3-H shift from the $\mathrm{CH}$ group as in Figure 7 was also considered; but again the activation barriers found were significantly higher than in Figure 7. Hence, we must conclude that the most favorable mechanism for the loss of $\mathrm{H}_{2} \mathrm{~S}$ has its origin in the most stable salt-bridge complex $\boldsymbol{a}(\boldsymbol{z})$.

\subsubsection{Coulomb explosions}

One of the signatures of the experimental electrospray spectra of $[\mathrm{Ca}(\mathrm{Cys})]^{2+}$ is the Coulomb explosion into $\mathrm{NH}_{4}^{+}+\left[\mathrm{C}_{3}, \mathrm{O}_{2}, \mathrm{~S}, \mathrm{H}_{3}\right]^{+}$. Obviously, the precursors for these processes should be the salt bridge complexes $\boldsymbol{a}(\boldsymbol{z})-\boldsymbol{f}(\boldsymbol{z})$, where the presence of a $\mathrm{NH}_{3}$ group is the ideal starting point to generate $\mathrm{NH}_{4}{ }^{+}$ions through an appropriate proton transfer. After a careful analysis of these processes two different proton transfer can be envisaged, those in which the proton comes from the -SH group, and those in which this proton comes from the neighboring $-\mathrm{CH}_{2}$ group. The first of these processes is the one observed when the starting structure is the most stable salt-bridge complex $\boldsymbol{a}(\boldsymbol{z})$. In this process, the activation barrier is associated with the weakening of the $\mathrm{C}-\mathrm{NH}_{3}$ bond which, as shown in Figure 8a, is accompanied however by a 1,2-H shift from the $\mathrm{CH}_{2}$ group to the $\mathrm{CH}$ one previously attached to the departing $\mathrm{NH}_{3}$ group. The process proceeds downhill as the $\mathrm{NH}_{3}$ molecule approaches to the terminal - $\mathrm{SH}$ group. The last shoulder observed in the energy profile corresponds to the proton transfer from the $-\mathrm{SH}$ group towards the ammonia molecule, to finally yield monocation $\boldsymbol{C}_{\boldsymbol{1}}+\mathrm{NH}_{4}^{+}$. 


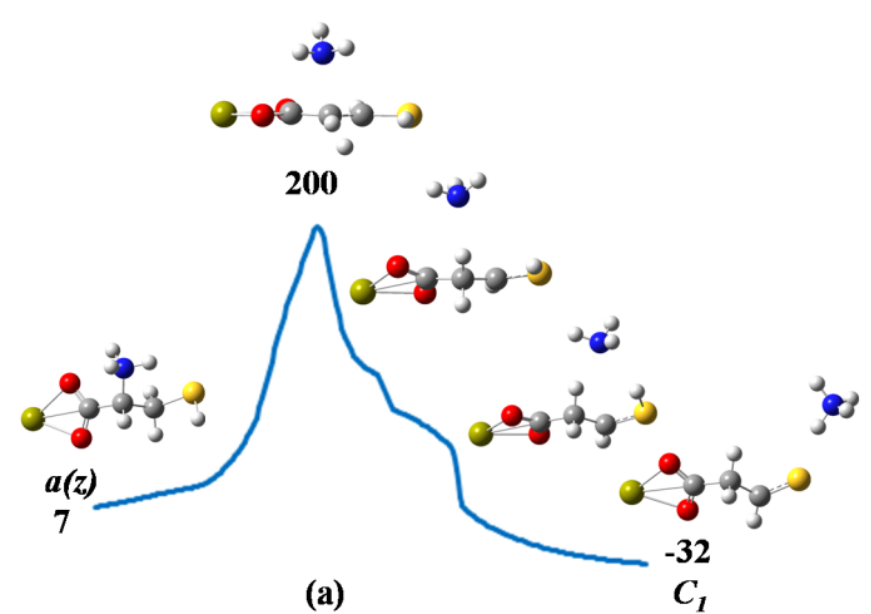

(a)

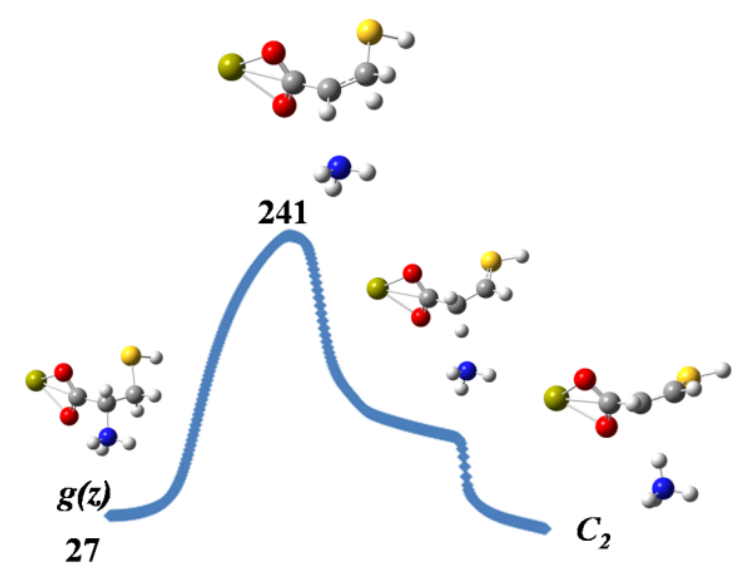

(b)

12

Figure 8. Potential enthalpy curves corresponding to the two mechanisms associated with the Coulomb explosions yielding $\mathrm{NH}_{4}{ }^{+}$. Relative enthalpies $\left(\mathrm{kJ} \mathrm{mol}^{-1}\right)$ are defined with respect to the global minimum $\boldsymbol{a}$.

A change in the conformation of the $-\mathrm{CH}-\mathrm{CH}_{2}-\mathrm{SH}$ tail leads to a new conformer $\boldsymbol{g}(z)$ which lies 27 $\mathrm{kJ} \mathrm{mol}^{-1}$ higher in energy. This new conformer also undergoes a Coulomb explosion yielding $\mathrm{NH}_{4}{ }^{+}$ but through a mechanism in which the proton transfer to form the ammonium ion comes from the $-\mathrm{CH}_{2}$ group rather than from the $-\mathrm{SH}$ group. Both the products and the activation barrier lie higher in energy than the corresponding ones in Figure 8a, so we should assume, in the absence of nonstatistical processes, that $\boldsymbol{C}_{\boldsymbol{I}}$ should be the ion which accompany $\mathrm{NH}_{4}{ }^{+}$in these Coulomb explosion processes.

\section{Conclusions}

The unimolecular decomposition of collision-activated $[\mathrm{Ca}(\mathrm{Cys})]^{2+}$ ions produced through electrospray ionization, is dominated by three competitive processes, namely the loss of ammonia, a Coulomb explosion yielding, $\mathrm{NH}_{4}{ }^{+}$and $\left[\mathrm{CaC}_{3} \mathrm{H}_{3} \mathrm{O}_{2} \mathrm{~S}\right]^{+}$and the loss of $\mathrm{H}_{2} \mathrm{~S}$. The observation of peaks corresponding to $\mathrm{m} / \mathrm{z}$ of 98.95 indicates that the $\left[\mathrm{CaC}_{3} \mathrm{H}_{3} \mathrm{O}_{2} \mathrm{~S}\right]^{+}$produced in the aforementioned Coulomb explosion undergo subsequent fragmentations. Similarly, the detection of lighter $\left[\mathrm{C}_{3} \mathrm{H}_{3} \mathrm{OS}\right]^{+}$and $\left[\mathrm{C}_{2} \mathrm{H}_{3} \mathrm{~S}\right]^{+}$monocations, indicate that the $\left[\mathrm{CaC}_{3} \mathrm{H}_{4} \mathrm{O}_{2} \mathrm{~S}\right]^{2+}$ dications produced by the loss of ammonia, undergo new Coulomb explosions in which the accompanying monocation 
is $[\mathrm{CaOH}]^{+}$. The cation $\left[\mathrm{C}_{3} \mathrm{H}_{3} \mathrm{OS}\right]^{+}$so produced would finally yield $\left[\mathrm{C}_{2} \mathrm{H}_{3} \mathrm{~S}\right]^{+}$by the loss of carbon monoxide. Alternatively, the aforementioned $\left[\mathrm{CaC}_{3} \mathrm{H}_{4} \mathrm{O}_{2} \mathrm{~S}\right]^{2+}$ dications, also lead to lighter $\left[\mathrm{CaCO}_{2}\right]^{2+}$ and $\left[\mathrm{CaC}_{2} \mathrm{H}_{4} \mathrm{~S}\right]^{2+}$ dications by the loss of $\mathrm{C}_{2} \mathrm{H}_{4} \mathrm{~S}$ and $\mathrm{CO}_{2}$, respectively. A comparison of this behavior with that exhibited by other aminoacids such as glycine ${ }^{[13]}$ or other small biochemical systems as urea, ${ }^{[29]}$ thiourea, ${ }^{[30]}$ selenourea ${ }^{[14 a]}$ or uracil, ${ }^{[31]}$ may permit to start foreseeing reactivity trends of relevance both in biochemistry and gas-phase reactivity.

A detailed exploration of the $\mathrm{Ca}^{2+} / \mathrm{Cys}$ potential energy surface indicates that the structures in which the metal dication interacts with the carboxylate group of the zwitterionic form of Cys are at the origin of the different reaction pathways leading to the observed product ions, even though they lie higher in energy than the adduct in which the metal interacts simultaneously with the carbonyl oxygen, the amino and the SH group of its canonical form. The interaction between metal cation and the base is essentially electrostatic, the calculated binding energy being $560 \mathrm{~kJ} \mathrm{~mol}^{-1}$.

\section{Acknowledgments}

This work has been partially supported by the DGI Projects No. CTQ2012-35513-C02, by the Project MADRISOLAR2, Ref.: S2009PPQ/1533 of the Comunidad Autónoma de Madrid, and by Consolider on Molecular Nanoscience CSC2007-00010. A generous allocation of computing time at the CCC of the UAM is also acknowledged.

\section{References}

[1] S. K. Tandon, S. Prasad and S. Singh, J. Appl. Toxic. 2002, 22, 67-71.

[2] M. Belcastro, T. Marino, N. Russo and M. Toscano, J. Mass Spectrom. 2005, 40, 300-306.

[3] a) T. Meinnel, S. Blanquet and F. Dardel, J. Mol. Biol. 1996, 262, 375-386; b) O. V. Nemirovskiy and M. L. Gross, J. Am. Soc. Mass Spectrom. 1996, 7, 977-980; c) O. V. Nemirovskiy and M. L. Gross, J. Am. Soc. Mass Spectrom. 1998, 9, 1285-1292; d) I. Endo, M. Nojiri, M. Tsujimura, M. Nakasako, S. Nagashima, M. Yohda and M. Odaka, J. Inorg. Biochem. 2001, 83, 247-253; e) A. Miyanaga, S. Fushinobu, K. Ito and T. Wakagi, Biochem. Biophys. Res. Comm. 2001, 288, 1169-1174; f) C. Mathe, T. A. Mattioli, O. Horner, M. Lombard, J. M. Latour, M. Fontecave and V. Niviere, J. Am. Chem. Soc. 2002, 124, 4966-4967; g) N. M. Giles, A. B. Watts, G. I. Giles, F. H. Fry, J. A. Littlechild and C. Jacob, Chem. Biol. 2003, 10, 677-693; h) R. Spezia, G. 
Tournois, J. Tortajada, T. Cartailler and M. P. Gaigeot, Phys. Chem. Chem. Phys. 2006, 8, 20402050; i) W. Buchmann, R. Spezia, G. Tournois, T. Cartailler and J. Tortajada, J. Mass Spectrom. 2007, 42, 517-526.

[4] E. C. Kendall and I. F. Nord, J. Biol. Chem. 1926, 69, 295-337.

[5] N. R. Jena, P. C. Mishra and S. Suhai, J. Phys. Chem. B 2009, 113, 5633-5644.

[6] I. Daizadeh, D. M. Medvedev and A. A. Stuchebrukhov, Mol. Biol. Evol. 2002, 19, 406-415.

[7] K. E. Hightower, C. C. Huang, P. J. Casey and C. A. Fierke, Biochemistry 1998, 37, 1555515562.

[8] H. Sigel, Chem. Soc. Rev. 1993, 22, 255-267.

[9] A. Eizaguirre, A. M. Lamsabhi, O. Mó and M. Yáñez, Theoret. Chem. Acc. 2011, 128, 457-464

[10] a) C. C. Ashley, T. J. Lea, I. P. Mulligan, R. E. Palmer and S. J. Simnett, Adv. Exp. Med. Biol. 1993, 332, 97-115; b) P. J. Silver, R. J. Michalak and S. M. Kocmund, J. Pharmacol. Exp. Therap. 1985, 232, 595-601.

[11] A. A. Saboury, M. S. Atri, M. H. Sanati, A. A. Moosavi-Movahedi and K. Haghbeen, Int. J. Biol. Macromol. 2005, 36, 305-309.

[12] a) D. Schroder and H. Schwarz, J. Phys. Chem. A 1999, 103, 7385-7394; b) D. S. Schroder, H. Schwarz, J. Wu and C. Wesdemiotis, Chem. Phys. Lett. 2001, 343, 258-264; c) N. G. Tsierkezos, J. Roithova, D. Schroder, I. E. Molinou and H. Schwarz, J. Phys. Chem. B 2008, 112, 4365-4371; d) D. Schroder, L. Duchackova, J. Tarabek, M. Karwowska, K. J. Fijalkowski, M. Oncak and P. Slavicek, J. Am. Chem. Soc. 2011, 133, 2444-2451; e) S. Rochut, J. Roithova, D. Schroder, F. R. Novara and H. Schwarz, J. Am. Soc. Mass Spectrom. 2008, 19, 121-125; f) N. G. Tsierkezos, M. Buchta, P. Holy and D. Schroder, Rap. Comm. Mass Spectrom. 2009, 23, 1550-1556.

[13] I. Corral, O. Mó, M. Yáñez, J. Y. Salpin, J. Tortajada, D. Moran and L. Radom, Chem. Eur. J 2006, 12, 6787-6796.

[14] a) C. Trujillo, O. Mó, M. Yáñez, J. Tortajada and J.-Y. Salpin, J. Phys. Chem. B 2008, 112, 5479-5486; b) A. Eizaguirre, O. Mo, M. Yanez and J. Y. Salpin, Phys. Chem. Chem. Phys. 2011, 13, 18409-18417.

[15] M. J. Frisch, G. W. Trucks, H. B. Schlegel, G. E. Scuseria, M. A. Robb, J. R. Cheeseman, G. Scalmani, V. Barone, B. Mennucci, G. A. Petersson, H. Nakatsuji, M. Caricato, X. Li, H. P. Hratchian, A. F. Izmaylov, J. Bloino, G. Zheng, J. L. Sonnenberg, M. Hada, M. Ehara, K. Toyota, R. Fukuda, J. Hasegawa, M. Ishida, T. Nakajima, Y. Honda, O. Kitao, H. Nakai, T. Vreven, J. J. A. Montgomery, J. E. Peralta, F. Ogliaro, M. Bearpark, J. J. Heyd, E. Brothers, K. N. Kudin, V. N. Staroverov, T. Keith, R. Kobayashi, J. Normand, K. Raghavachari, A. Rendell, J. C. Burant, S. S. Iyengar, J. Tomasi, M. Cossi, N. Rega, J. M. Millam, M. Klene, J. E. Knox, J. B. Cross, V. Bakken, C. Adamo, J. Jaramillo, R. Gomperts, R. E. Stratmann, O. Yazyev, A. J. Austin, R. Cammi, C. Pomelli, J. W. Ochterski, R. L. Martin, K. Morokuma, V. G. Zakrzewski, G. A. Voth, P. Salvador, J. J. Dannenberg, S. Dapprich, A. D. Daniels, O. Farkas, J. B. Foresman, J. V. Ortiz, J. Cioslowski and D. J. Fox in Gaussian 09, Revision C.01, Vol. Gaussian, Inc. Wallingford CT, 2010.

[16] in Avogadro: an open-source molecular builder and visualization tool. Version 1.0.0. http://avogadro.openmolecules.net/, Vol. 2010.

[17] a) A. D. Becke, J. Chem. Phys. 1993, 98, 5648-5652; b) C. Lee, W. Yang and R. G. Parr, Phys. Rev. B 1988, 37, 785-789.

[18] a) I. Corral, O. Mó, M. Yáñez, A. Scott and L. Radom, J. Phys. Chem. A 2003, 107, 1045610461; b) I. Corral, C. Trujillo, J. Y. Salpin and M. Yáñez in Ca2+ reactivity in the gas phase. Bonding, catalytic effects and coulomb explosions, Vol. 12 Eds.: P.-. Paneth and A. DybalaDefratyka), Springer, London, 2010.

[19] a) R. F. W. Bader, Atoms in Molecules. A Quantum Theory, Clarendon Press, Oxford, 1990, p; b) C. F. Matta and R. J. Boyd, The Quantum Theory of Atoms in Molecules, Wiley-VCH, Weinheim, 2007, p.

[20] A. Savin, R. Nesper, S. Wengert and T. F. Fäsler, Angew. Chem. Int. Ed. Engl. 1997, 36, 18081832. 
[21] T. A. Keith in AIMAll (Version 10.07.25), , Vol. aim.tkgristmill.com, 2010.

[22] S. Noury, X. Krokidis, F. Fuster and B. Silvi, Comput. Chem. 1999, 23, 597-604.

[23] NIST Chemistry Webbook. Standard Reference Database Number 69. Eds. P.J. Linstrom and W.G. Mallard, Release June 2005, National Institute of Standards and Technology, Gaithersburg MD, 20899 (http://webbook.nst.gov). 2013.

[24] a) Peter B. Armentrout, Erin I. Armentrout, Amy A. Clark, Theresa E. Cooper, E. M. S. Stennett and D. R. Carl, J. Phys. Chem. B 2010, 114, 3927-3937; b) P. B. Armentrout, Y. Chen and M. T. Rodgers, J. Phys. Chem. A 2012, 116, 3989-3999.

[25] P. B. Armentrout, S. J. Ye, A. Gabriel and R. M. Moision, J. Phys. Chem. B 2010, 114, 39383949.

[26] R. Shankar, P. Kolandaivel and L. Senthilkumar, J. Phys. Org. Chem. 2011, 24, 553-567.

[27] A. Lamsabhi, O. Mó and M. Yáñez, Can. J. Chem. 2010, 88, 759-768.

[28] A. E. Reed, L. A. Curtiss and F. Weinhold, Chem. Rev. 1988, 88, 899-926.

[29] I. Corral, O. Mó, M. Yáñez, J.-Y. Salpin, J. Tortajada and L. Radom, J. Phys. Chem. A 2004, $108,10080-10088$.

[30] C. Trujillo, O. Mó, M. Yáñez, J. Y. Salpin and J. Tortajada, ChemPhysChem 2007, 8, 1330.

[31] C. Trujillo, A. Lamsabhi, O. Mó, M. Yáñez and J. Y. Salpin, Int. J. Mass Spectrom. 2011, 306, 27-36. 
Supporting Information

Modelling aminoacid-metal dication interactions: cysteine- $\mathrm{Ca}^{2+}$ reactions in the gas phase.

Marcela Hurtado, Manuel Monte, Al Mokhtar Lamsabhi, Manuel Yáñez, Otilia Mó, and Jean-Yves Salpin

Contribution from Departamento de Química, C-13. Universidad Autónoma de Madrid. Cantoblanco, ES-28049 Madrid, Spain, and Université d'Evry Val d'Essonne, Laboratoire Analyse et Environnement pour la Biologie et l'Environnement, CNRS UMR 8587, Bâtiment Maupertuis, BouleVard François Mitterrand, 91025 EVry Cedex, France.

\section{Supporting Information (total of 4 pages)}




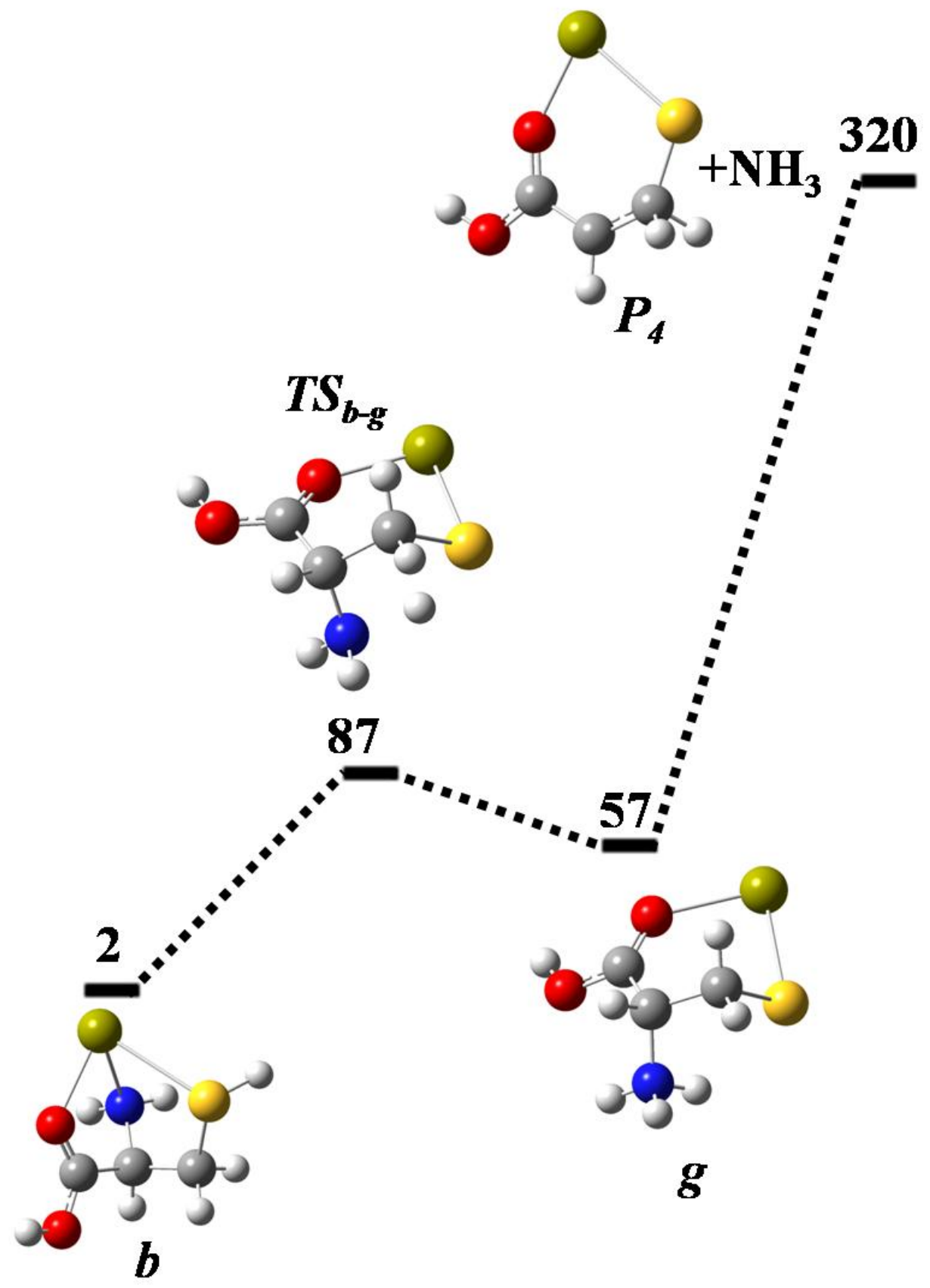

Figure S1. Energy profiles associated with the loss of ammonia from salt-bridge complexes. Relative energies $\left(\mathrm{kJ} \mathrm{mol}^{-1}\right)$ are calculated with respect to the global minimum $\boldsymbol{a}$. 

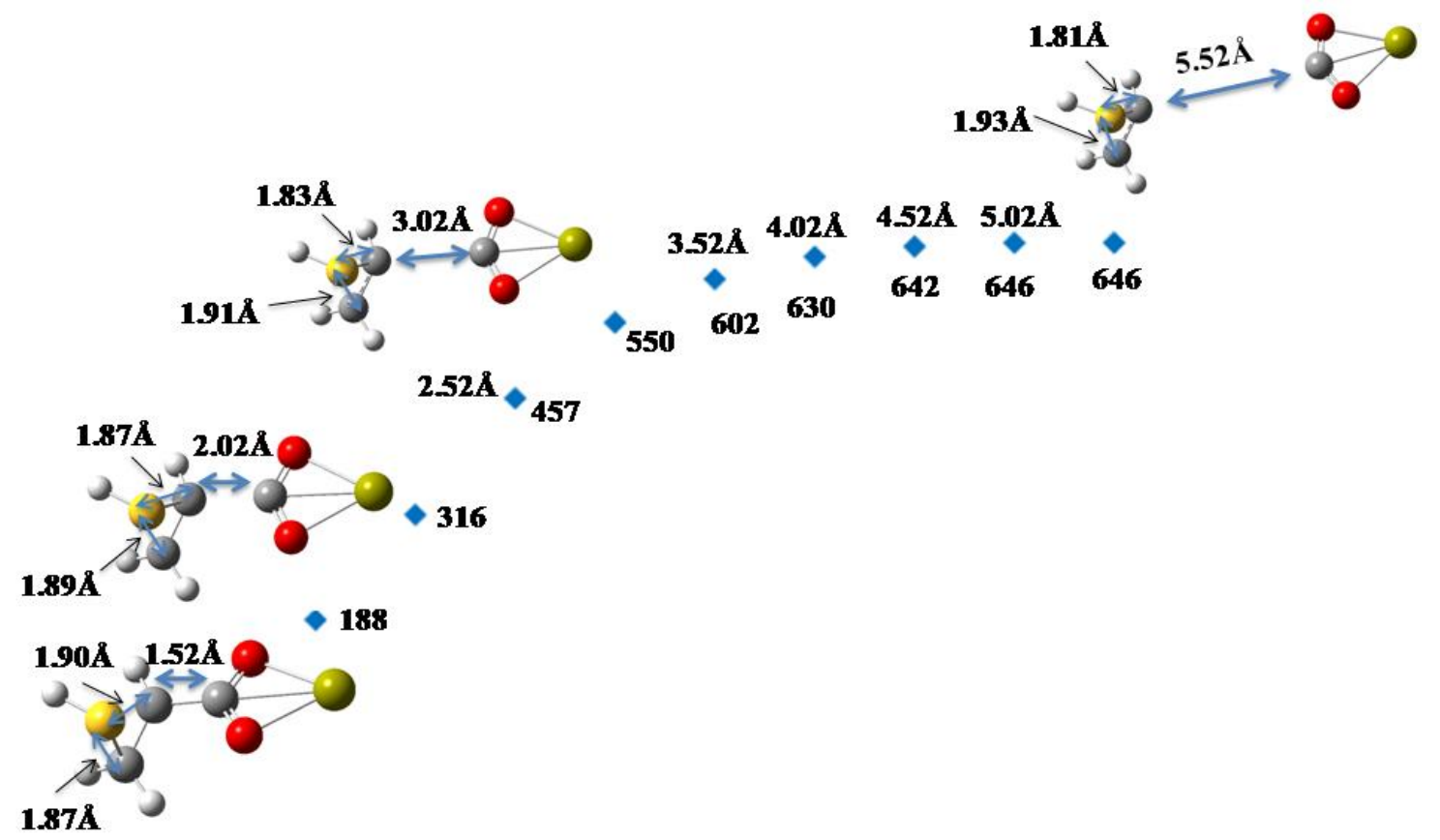

Figure S2. Scans for bond cleavage $\mathrm{CH}-\mathrm{CO}_{2} \mathrm{Ca}$ from 1.52 to $5.52 \AA$. Energy changes are in the range $188-646 \mathrm{~kJ} \mathrm{~mol}^{-1}$.

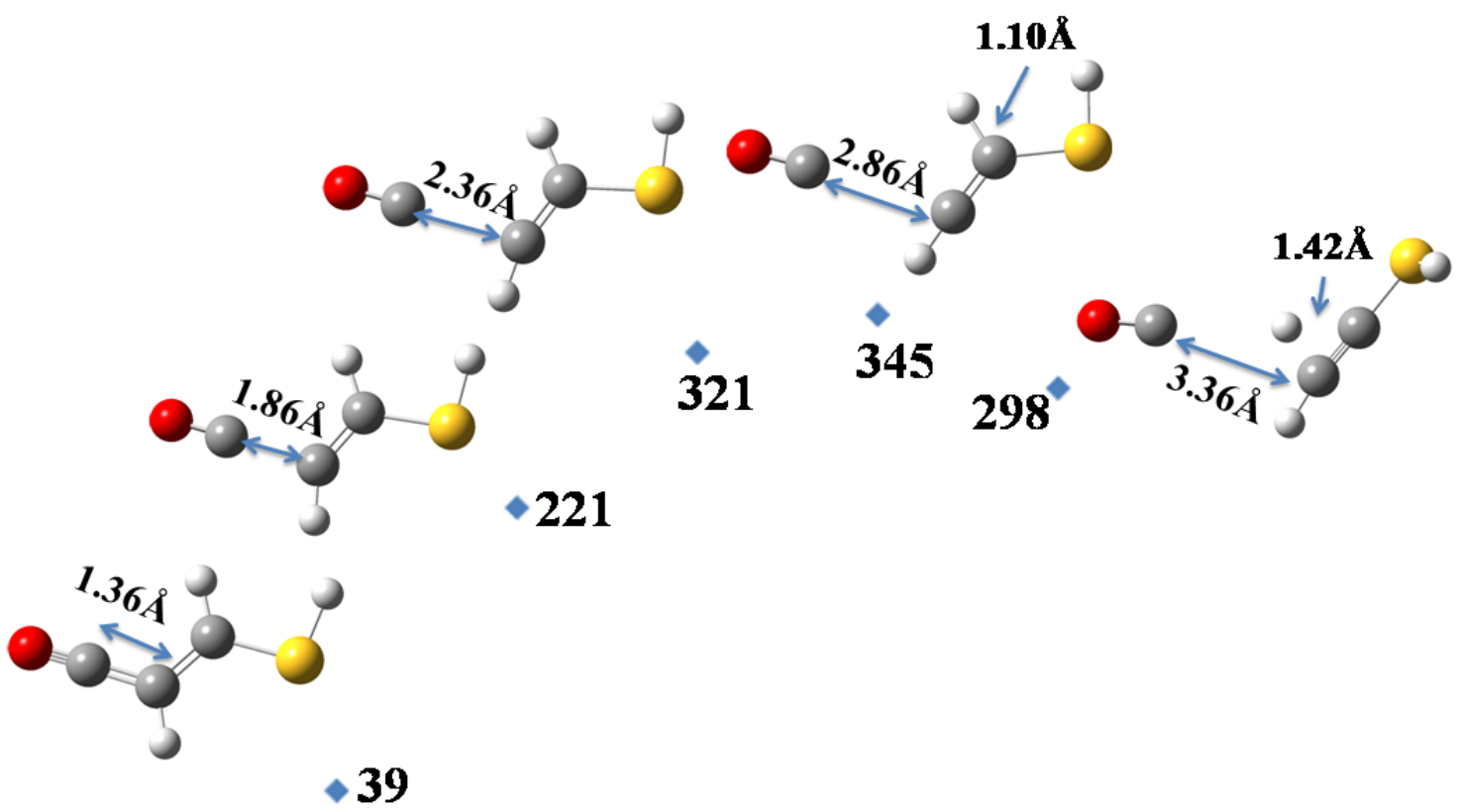

Figure S3. Scans for $\mathrm{CH}-\mathrm{CO}$ bond cleavage from 1.36 to $3.36 \AA$. Energy changes are in the range 39 to $298 \mathrm{~kJ} \mathrm{~mol}^{-1}$. 


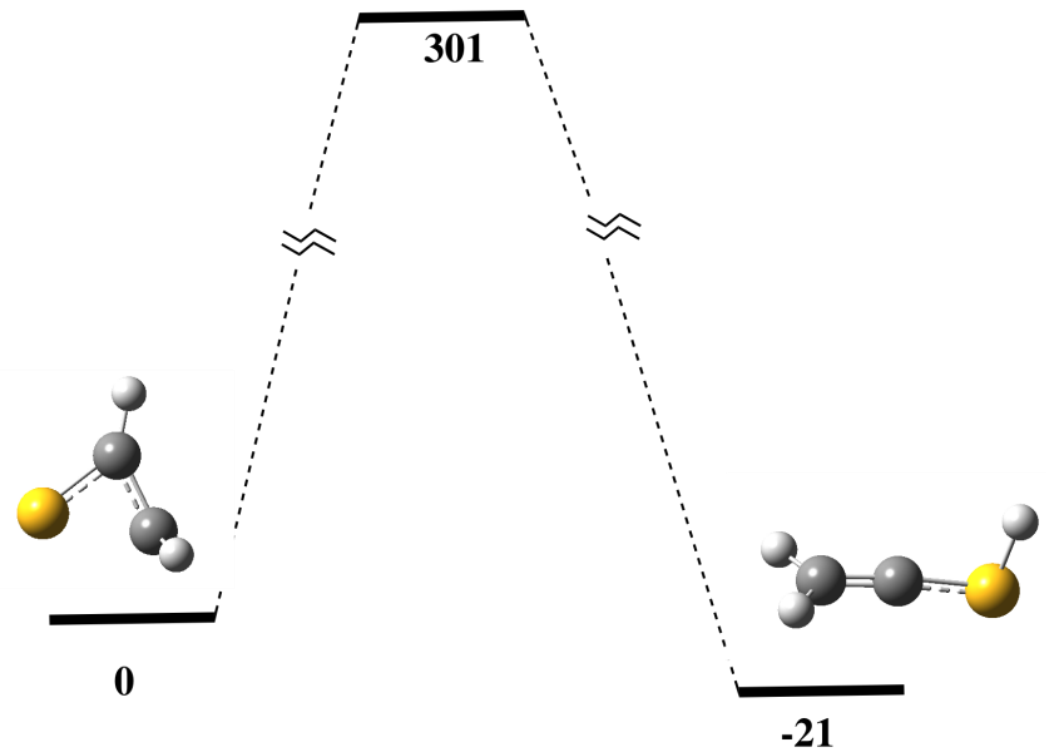

Figure S4. Energy barrier connecting the conformers issued from the sequential loss of ammonia, $\mathrm{CaOH}^{+}$and $\mathrm{CO}$. Relative energies $\left(\mathrm{kJ} \mathrm{mol}^{-1}\right)$ are calculated with respect to the global minimum $\boldsymbol{a}$.

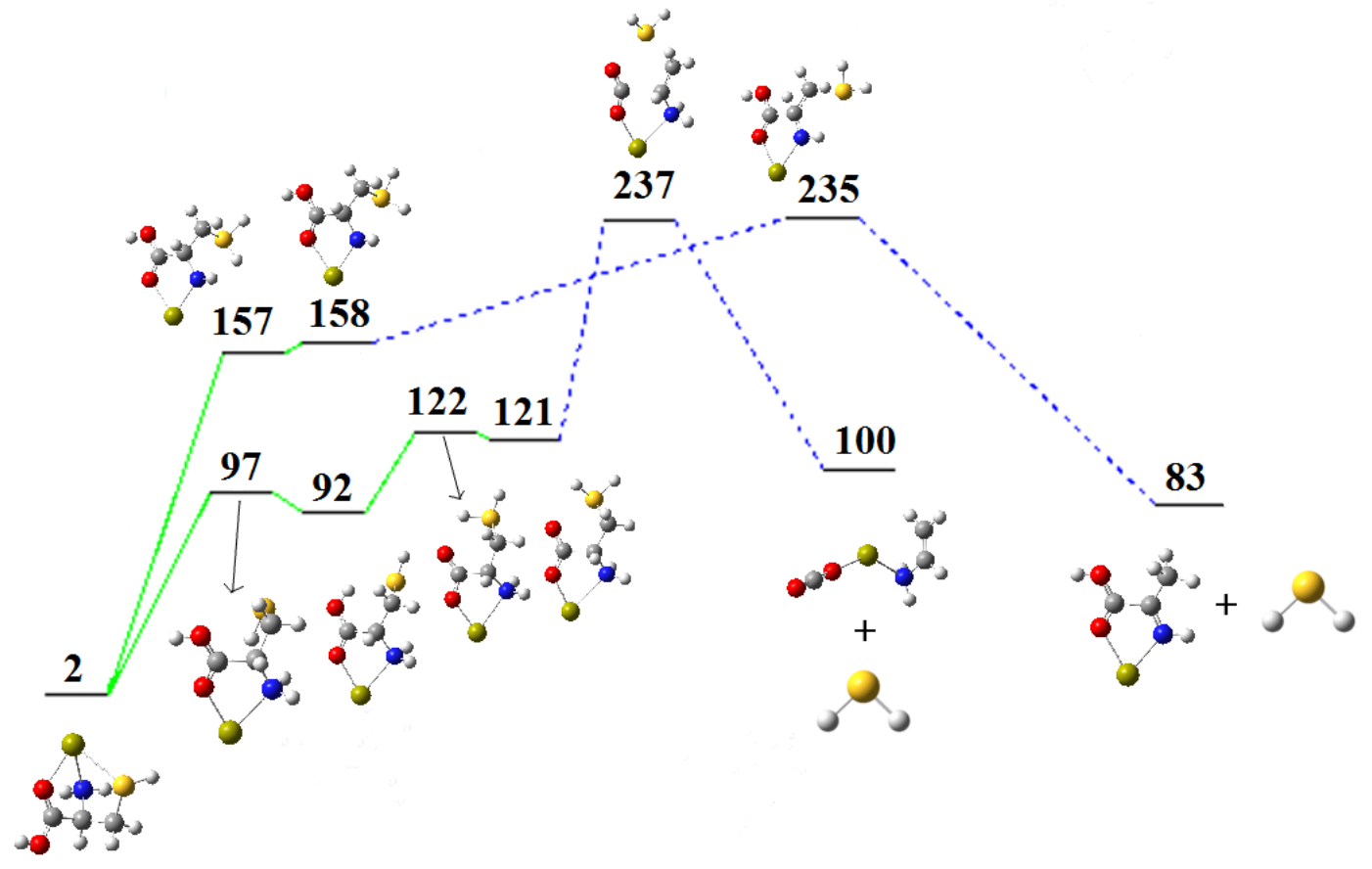

Figure S5. Energy profile associated with the loss of $\mathrm{H}_{2} \mathrm{~S}$ from global minimum $\boldsymbol{b}$. Relative energies $\left(\mathrm{kJ} \mathrm{mol}^{-1}\right)$ are with respect to the global minimum $\boldsymbol{a}$ of the potential energy surface. 